\title{
Control of nitrification/denitrification in an onsite two-chamber intermittently aerated membrane bioreactor with alkalinity and carbon addition: Model and experiment
}

\author{
Mahamalage Kusumitha Perera ${ }^{a, *}$, James D. Englehardt ${ }^{\text {a }}$, George Tchobanoglous ${ }^{\text {, }}$, \\ Reza Shamskhorzani ${ }^{\mathrm{c}}$ \\ a Civil, Architectural, and Environmental Engineering, University of Miami, PO Box 248294, Coral Gables, FL 33124-0630, USA \\ b Department of Civil and Environmental Engineering, University of California Davis, One Shields Avenue, Davis, CA 95616, USA \\ c Bio-Microbics, 8450 Cole Parkway, Shawnee, KS 66227, USA
}

\section{A R T I C L E I N F O}

\section{Article history:}

Received 7 July 2016

Received in revised form

8 January 2017

Accepted 10 February 2017

Available online 20 February 2017

\section{Keywords:}

Membrane bioreactor

Model

Direct potable reuse

Nitrification

Denitrification

Aeration

\begin{abstract}
A B S T R A C T
Denitrifying membrane bioreactors (MBRs) are being found useful in water reuse treatment systems, including net-zero water (nearly closed-loop), non-reverse osmosis-based, direct potable reuse (DPR) systems. In such systems nitrogen may need to be controlled in the MBR to meet the nitrate drinking water standard in the finished water. To achieve efficient nitrification and denitrification, the addition of alkalinity and external carbon may be required, and control of the carbon feed rate is then important. In this work, an onsite, two-chamber aerobic nitrifying/denitrifying MBR, representing one unit process of a net-zero water, non-reverse osmosis-based DPR system, was modeled as a basis for control of the MBR internal recycling rate, aeration rate, and external carbon feed rate. Specifically, a modification of the activated sludge model ASM2dSMP was modified further to represent the rate of recycling between separate aerobic and anoxic chambers, rates of carbon and alkalinity feed, and variable aeration schedule, and was demonstrated versus field data. The optimal aeration pattern for the modeled reactor configuration and influent matrix was found to be $30 \mathrm{~min}$ of aeration in a $2 \mathrm{~h}$ cycle $\left(104 \mathrm{~m}^{3}\right.$ air/d per $1 \mathrm{~m}^{3} /$ $\mathrm{d}$ average influent), to ultimately meet the nitrate drinking water standard. Optimal recycling ratios (inter-chamber flow to average daily flow) were found to be 1.5 and 3 during rest and mixing periods, respectively. The model can be used to optimize aeration pattern and recycling ratio in such MBRs, with slight modifications to reflect reactor configuration, influent matrix, and target nitrogen species concentrations, though some recalibration may be required.
\end{abstract}

() 2017 Elsevier Ltd. All rights reserved.

\section{Introduction}

Submerged membrane bioreactors (SMBRs), or membrane bioreactors (MBRs) with membrane installed in the aeration tank, have attracted significant attention for municipal wastewater treatment due to their efficient removal of organics and small footprint (Judd, 2010). This efficiency has been attributed to high mixed liquor suspended solids (MLSS) concentrations due to longer sludge retention times (SRTs) (Hai et al., 2014; Henze et al., 2008; Zarragoitia-González et al., 2008), and the resulting high effluent

\footnotetext{
* Corresponding author.

E-mail addresses: m.perera@miami.edu (M.K. Perera), jenglehardt@miami.edu (J.D. Englehardt).
}

quality makes the system particularly attractive for direct potable water reuse (Abegglen et al., 2008). For example, an SMBR has been used as the secondary treatment step in a nearly closed-loop, nonreverse osmosis-based direct potable water reuse (DPR) treatment system, preceding filtration and advanced oxidation chemical treatment, to substantially mineralize organic mass (Gassie et al., 2016; Wu and Englehardt, 2016). This approach, termed net-zero water (NZW) management, can provide energy-positive treatment, i.e. save more energy than is used to operate the plant, while addressing water shortage (Wu and Englehardt, 2015).

In advanced oxidation-based DPR systems which do not employ high-energy reverse osmosis or other salt-separation method, control of nitrate/nitrite is important to meet drinking water standards in the treated water (Gassie et al., 2016; Wu and Englehardt, 2016, 2015). In such systems, the addition of external 
alkalinity and/or carbon to the MBR aerobic and anoxic zones, respectively, may be needed to maintain nitrifier/denitrifier growth (Abegglen et al., 2008), depending on their concentrations in the influent wastewater (Agathos and Reineke, 2003; Henze et al., 2008; Ivanov, 2011; Peng et al., 2007; Tchobanoglous et al., 2003). However, the addition of these external substrates may need to be controlled carefully (Dalmau et al., 2013; Olsson and Newell, 1999).

Mathematical modeling may be a particularly useful tool for the control of effluent nitrogen in DPR systems. Such models originally focused on either the biological process or the physical filtration process. However, integrated models (Mannina et al., 2010) have been developed more recently to address interactions between the two processes, by connecting the biological and physical submodels via principal influential variables, and these models have been shown to predict experimental results more accurately (Di Bella et al., 2008; Mannina et al., 2011b; Zarragoitia-González et al., 2008). Also, because the biological processes employed in MBRs are essentially similar to those of activated sludge processes, activated sludge models (ASMs) have been directly applied in modeling biological sub-models in MBRs (Fenu et al., 2010; Henze et al., 2000). However, membrane fouling is a significant factor in MBR performance, and soluble microbial products (SMPs), constituents have been found to be the principal cause of fouling in MBRs (Benyahia et al., 2013; Di Bella et al., 2008; Hai et al., 2014; Jiang et al., 2008; Zuthi et al., 2013). Hence, modified ASMs include SMPs explicitly, and recent predictions with such models have compared fairly well with experimental pilot plant results (Di Bella et al., 2008; Jiang et al., 2008; Mannina et al., 2011b).

MBR configurations include both alternating aerobic and anoxic zones within a single compartment, as well as separate aerobic and anoxic compartments with internal recycling (Kim et al., 2010), and current integrated MBR models can predict nitrification and denitrification based on the recycle ratio, i.e. the ratio of inter-chamber flow to average daily flow (Kim et al., 2010). Results of previous integrated models (Di Bella et al., 2008; Mannina et al., 2011b) suggest an effluent $\mathrm{NO}_{3}^{-}$concentration of $\sim 35 \mathrm{mg} / \mathrm{L}$, above US potable water standards (EPA, 2015), without the addition of external alkalinity, e.g. as calcium carbonate, and carbon substrate, e.g. as an alcohol or sugar, with municipal raw sewage as influent. However, these studies were not focused on nitrogen removal, and recent work has demonstrated better nitrogen removal, e.g. $\sim 17 \mathrm{mg} / \mathrm{L}$ (Cosenza et al., 2013) and $\sim 8.8 \mathrm{mg} / \mathrm{L}$ (Dalmau et al., 2013) effluent TN, with addition of carbon substrate.

NZW systems can be implemented onsite, due to lack of need for routine residuals disposal, and such applications require simplicity of operation. In that context, aeration rate may be adjustable only through scheduling. In fact, intermittent aeration can enhance denitrification efficiency (Capodici et al., 2015; Lim et al., 2007), and dramatically reduce the recycling ratio in MBRs (Kim et al., 2007). However, aeration schedule interacts with recycling ratio in its influence on nitrification/denitrification. Hence, models are needed to optimize the addition of carbonaceous substrate, together with aeration schedule and recycle ratio, to understand and optimize nitrogen removal efficiency for process design and control.

The purpose of this paper is to present a model of an onsite aerobic nitrifying/denitrifying MBR with variable mixing between separate aerobic and anoxic chambers, variable aeration schedule, and external alkalinity and carbon addition, useful in operating netzero water DPR and other MBR-based treatment systems to minimize effluent $\mathrm{NO}_{3}^{-}$concentration. Model components were adapted from previous work (Di Bella et al., 2008; Mannina et al., 2011b), and modified to account for external alkalinity and carbon addition, variable aeration schedule, and mixing between dual compartments of an SMBR. Kinetic parameters were calibrated, and the model was demonstrated versus data collected in current research (Wu and Englehardt, 2015) on a net-zero water DPR system. Observations and recommendations for future work are presented. Physical filtration process modeling was outside of the scope of this work due to the essentially constant filtration rate over the experimental period.

\section{Materials and methods}

A $500 \mathrm{gal} / \mathrm{d}$ (design flow) BioBarrier- $\mathrm{N}^{\circledR}$ (BioMicrobics, Inc., Shawnee, KS), $4.15 \mathrm{~m}^{3}$ dual compartment MBR was installed as one component of a net-zero water, i.e. nearly closed-loop (85\% wastewater recycling), DPR system (with an average flow of 260 $\mathrm{gal} / \mathrm{d}$ ) at a four-bedroom, four-bath residence hall apartment with dishwasher and washing machine described previously (Englehardt et al., 2013). Wastewater from the apartment was

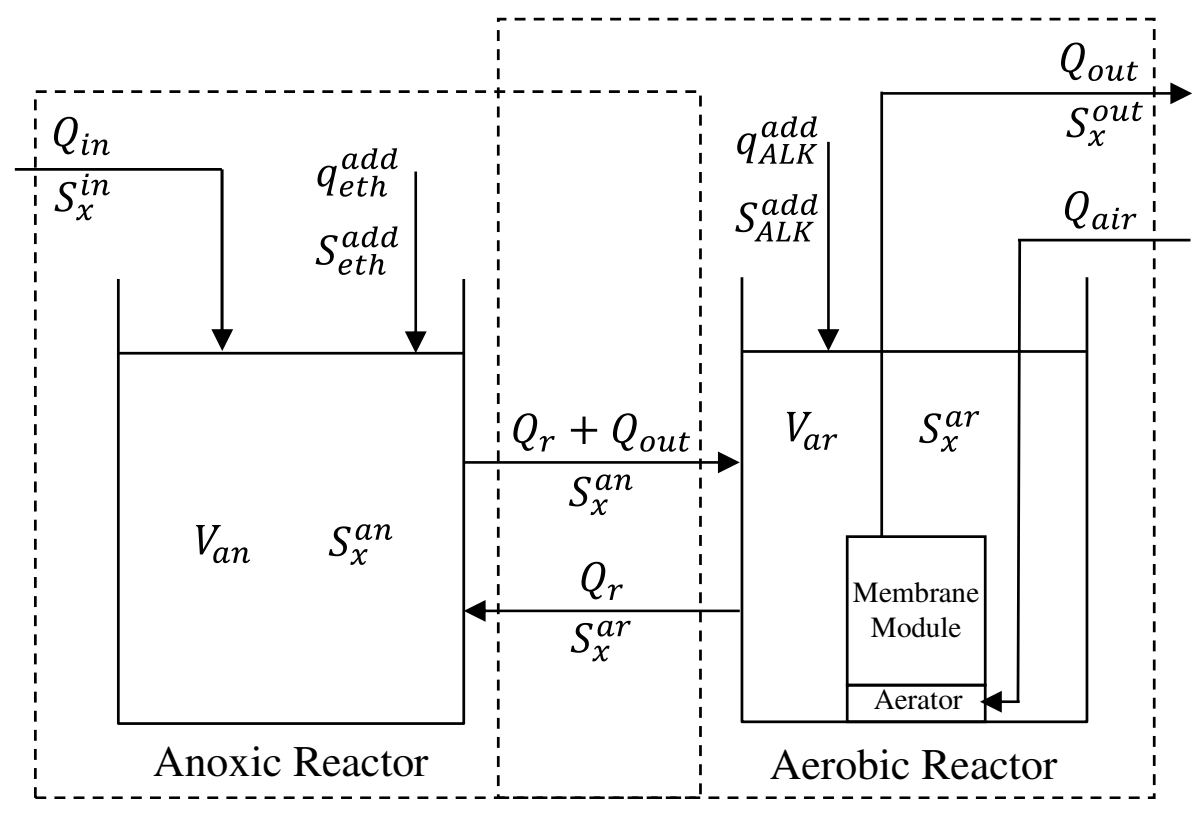

Fig. 1. Schematic diagram of the reactor. 
Table 1

Nomenclature.

\begin{tabular}{|c|c|c|}
\hline Symbol & Description & Unit \\
\hline$\mu_{H}$ & Maximum specific growth rate of heterotrophs & $d^{-1}$ \\
\hline$\mu_{A}$ & Maximum specific growth rate of autotrophs & $d^{-1}$ \\
\hline$b_{H}$ & Decay rate of heterotrophs & $d^{-1}$ \\
\hline$b_{A}$ & Decay rate of autotrophs & $d^{-1}$ \\
\hline$Y_{H}$ & Heterotroph yield coefficient & $g C O D / g C O D$ \\
\hline$Y_{A}$ & Autotroph yield coefficient & $g C O D / g N$ \\
\hline$K_{a}$ & Ammonification coefficient & $m^{3} /(g C O D \cdot d)$ \\
\hline$K_{h}$ & Particulate hydrolysis maximum specific rate constant & $g C O D /(g C O D \cdot d)$ \\
\hline$K_{h, B A P}$ & Hydrolysis rate of biomass associated products (BAP) & $g C O D /(g C O D \cdot d)$ \\
\hline$f_{\text {BAP }}$ & Fraction of BAP produced during hydrolysis & - \\
\hline$K_{h, U A P}$ & Hydrolysis rate of utilization-associated products (UAP) & $g C O D /(g C O D \cdot d)$ \\
\hline$f_{U A P}$ & Fraction of UAP produced during cell growth & - \\
\hline$K_{s}$ & Saturation coefficient for organic matter & $m g / L$ \\
\hline$K_{\mathrm{OH}}$ & Heterotroph saturation coefficient for oxygen & $m g / L$ \\
\hline$K_{N O}$ & Saturation coefficient for nitrate & $m g / L$ \\
\hline$K_{N H}$ & Saturation coefficient for ammonia & $m g / L$ \\
\hline$K_{O A}$ & Autotroph saturation coefficient for oxygen & $m g / L$ \\
\hline$K_{X}$ & Hydrolysis half-velocity constant & $g C O D / g C O D$ \\
\hline$\eta_{g}$ & Correction factor for anoxic heterotrophic growth & - \\
\hline$\eta_{h}$ & Correction factor for anoxic hydrolysis & - \\
\hline$i_{x b}$ & Ammonia fraction in biomass & $g N / g C O D$ \\
\hline$i_{x p}$ & Ammonia fraction in particulate products & $g N / g C O D$ \\
\hline$f_{p}$ & Fraction of inert products by biomass & - \\
\hline$f_{b}$ & Fraction of inert converts in biomass & - \\
\hline$f$ & Substrate fraction below critical molecular size & - \\
\hline$R_{r}$ & Recycling ratio (rest mode) & - \\
\hline$R_{m}$ & Recycling ratio (mixing mode) & - \\
\hline$Q_{r}$ & Recycling flow rate & - \\
\hline$\alpha^{\text {OTR }}$ & Oxygen transfer correlation factor for wastewater & - \\
\hline$\beta^{\text {OTR }}$ & Salinity surface tension correlation factor & - \\
\hline$F^{O T R}$ & Fouling factor & - \\
\hline$C_{L}^{O T R}$ & Operating oxygen concentration & $m g / L$ \\
\hline$C_{\bar{S}, T, H}^{O T R}$ & Average DO saturation concentration in clean water in aerobic reactor at temperature $T$ and altitude $H$ & $m g / L$ \\
\hline$C_{S, 20}^{O T R}$ & DO saturation concentration in clean water at $20^{\circ} \mathrm{C}$ & $m g / L$ \\
\hline$E^{O T R}$ & $\mathrm{O}_{2}$ transfer efficiency of the aerator & - \\
\hline$Q_{\text {in }}$ & Influent flow rate & $L / d$ \\
\hline Qout & Effluent flow rate & $L / d$ \\
\hline$Q_{r}$ & Recycling flow rate & $L / d$ \\
\hline Qair & Air flow rate & scfm \\
\hline$V_{a n}$ & Volume of anoxic chamber & $m^{3}$ \\
\hline$V_{a r}$ & Volume of aerobic chamber & $m^{3}$ \\
\hline $\mathrm{R}$ & Rate of generation of any component & $m g /(L \cdot h r)$ \\
\hline$S_{x}^{\text {in }}$ & Concentration of any soluble substrate in the influent & $m g / L$ \\
\hline$S_{x}^{\text {out }}$ & Concentration of any soluble substrate in the effluent & $m g / L$ \\
\hline$\hat{S_{x}^{a n}}$ & Concentration of any soluble substrate in anoxic chamber & $m g / L$ \\
\hline$S_{i}^{a n}$ & Concentration of inert soluble organic matter in anoxic chamber & $m g / L$ \\
\hline$S_{s}^{a n}$ & Concentration of rbCOD in anoxic chamber & $m g / L$ \\
\hline$S_{B A P}^{a n}$ & Concentration of BAP in anoxic chamber & $m g / L$ \\
\hline$S_{U A P}^{a n}$ & Concentration of UAP in anoxic chamber & $m g / L$ \\
\hline$S_{O}^{a n}$ & Concentration of DO in anoxic chamber & $m g / L$ \\
\hline$S_{\mathrm{NO}}^{a n}$ & Concentration of nitrate nitrogen in anoxic chamber & $m g / L$ \\
\hline$S_{N H}^{a n}$ & Concentration of ammonia nitrogen in anoxic chamber & $m g / L$ \\
\hline$S_{N D}^{a n}$ & Concentration of soluble organic nitrogen in anoxic chamber & $m g / L$ \\
\hline$S_{A L K}^{a n}$ & Concentration of alkalinity as $\mathrm{CaCO}_{3}$ in anoxic chamber & $m g / L$ \\
\hline$X_{i}^{a n}$ & Concentration of inert suspended organic matter in anoxic chamber & $m g / L$ \\
\hline$X_{S}^{a n}$ & Concentration of slowly biodegradable substrate in anoxic chamber & $m g / L$ \\
\hline$X_{B H}^{a n}$ & Concentration of heterotrophic biomass in anoxic chamber & $m g / L$ \\
\hline$X_{B A}^{a n}$ & Concentration of autotrophic biomass in anoxic chamber & $m g / L$ \\
\hline$X_{N D}^{a n}$ & Concentration of particulate organic nitrogen in anoxic chamber & $m g / L$ \\
\hline$S_{x}^{a r}$ & Concentration of any soluble substrate in aerobic chamber & $m g / L$ \\
\hline$S_{i}^{a r}$ & Concentration of inert soluble organic matter in aerobic chamber & $m g / L$ \\
\hline$S_{s}^{a r}$ & Concentration of rbCOD in aerobic chamber & $m g / L$ \\
\hline$S_{B A P}^{a r}$ & Concentration of BAP in aerobic chamber & $m g / L$ \\
\hline$S_{U A P}^{\text {DAr }}$ & Concentration of UAP in aerobic chamber & $m g / L$ \\
\hline$S_{O}^{a r}$ & Concentration of DO in aerobic chamber & $m g / L$ \\
\hline$S_{N O}^{a r}$ & Concentration of nitrate nitrogen in aerobic chamber & $m g / L$ \\
\hline$S_{N H}^{a r}$ & Concentration of ammonia nitrogen in aerobic chamber & $m g / L$ \\
\hline$S_{N D}^{a r}$ & Concentration of soluble organic nitrogen in aerobic chamber & $m g / L$ \\
\hline$S_{A L K}^{a r}$ & Concentration of alkalinity as $\mathrm{CaCO}_{3}$ in aerobic chamber & $m g / L$ \\
\hline
\end{tabular}


Table 1 (continued)

\begin{tabular}{|c|c|c|}
\hline Symbol & Description & Unit \\
\hline$X_{i}^{a r}$ & Concentration of inert suspended organic matter in aerobic chamber & $m g / L$ \\
\hline$X_{s}^{a r}$ & Concentration of slowly biodegradable substrate in aerobic chamber & $m g / L$ \\
\hline$X_{B H}^{a r}$ & Concentration of heterotrophic biomass in aerobic chamber & $m g / L$ \\
\hline$X_{B A}^{a r}$ & Concentration of autotrophic biomass in acerobic chamber & $m g / L$ \\
\hline$X_{N D}^{a r}$ & Concentration of particulate organic nitrogen in aerobic chamber & $m g / L$ \\
\hline$S_{N 2}$ & Concentration of nitrogen gas released in denitrification & $m g / L$ \\
\hline
\end{tabular}

collected by $4.15 \mathrm{~m}^{3}$ septic tank, and pumped to the anoxic chamber of the MBR, equally-divided by perforated baffle from the downstream aerobic chamber. Chambers were periodically mixed by mixing blower, ON for 1 min every 10 min except during the filtration period. Effluent was pumped out through a flatmembrane module placed above the aerator in the aerobic chamber. The MBR aerator was set at the factory to cycle ON during filtration/discharge, and ON for $30 \mathrm{~min}$, OFF for $90 \mathrm{~min}$ otherwise. To achieve denitrification, and thereby meet the nitrate standard in the final treated drinking water produced by subsequent physicalchemical and advanced oxidation treatment, systems were installed to meter external alkalinity as calcium carbonate slurry to the MBR anoxic chamber for mixing with the aerobic zone, and carbonaceous substrate as ethanol to the anoxic chamber.

The pilot MBR was operated as follows. Septic tank supernatant was pumped to the modeled MBR, controlled by both water level floats and timer. Specifically, when the timer was activated, the pump was ON for $30 \mathrm{~s}$ every $3 \mathrm{~h}$, resulting in delivery of approximately $260 \mathrm{~L}$ water to the MBR. Based on the time of septic tank pump operation, $109 \mathrm{mg} / \mathrm{L}$ ethanol as external carbon source and $128 \mathrm{mg} / \mathrm{L} \mathrm{CaCO}_{3}$ (alkalinity) were metered to the anoxic chamber for nitrification/denitrification during the time period of the experiment. The aerobic zone was necessarily aerated throughout the filtration cycle, to maintain filtration flux. During non-filtration periods, termed relaxation periods, aeration was adjusted to the lowest setting, ON for $30 \mathrm{~min}$, OFF for $90 \mathrm{~min}$. Further, to achieve a high level of denitrification in this application, total daily aeration was reduced further by placing the MBR system master power on a timer, to operate $12 \mathrm{~h}$ /day (ON for $6 \mathrm{~h}$, OFF for $6 \mathrm{~h}$ ). The filtration pump was controlled by the water level floats, delivering approximately $800 \mathrm{~L}$ of filtered water to the dosing tank each time, the exact amount depending upon both the water level and the MBR timer. Membrane nominal pore size is $0.08 \mu \mathrm{m}$ in clean water, decreasing effectively to $0.02-0.04 \mu \mathrm{m}$ during operation. Solids were retained in the MBR for the entire two-year period of operation, $1 / 1 / 13-12 / 31 / 14$, during which time solids were estimated to accumulate at a rate of $\sim 0.12 \mathrm{~kg} / \mathrm{d}$. During this experiment, the effluent filtration rate through the membrane was approximately $4.2 \mathrm{~L} / \mathrm{min}\left(6 \mathrm{~m}^{3} / \mathrm{d}\right)$.

For purposes of modeling the system, a sampling campaign was carried out from 2nd December to 16th December 2013 with samples drawn from the septic tank, the anoxic zone and aerobic zones of the MBR, and from the $4.5 \mathrm{~m}^{3}$ "dosing tank" which collected effluent and discharged to downstream physical-chemical treatment. Samples were analyzed for chemical oxygen demand (COD), nitrate and total nitrogen. COD measurements were obtained using Hach $^{\circledR}$ Digestion COD Method 8000 Ultra Low Range and Low Range tests. Nitrate and total nitrogen was analyzed by the Hach ${ }^{\circledR}$ Nitrate Cadmium Reduction Method 8039, and Hach ${ }^{\circledR}$ Total Nitrogen Test 'N Tube ${ }^{\mathrm{TM}^{*}}$ Method 10071, respectively. Samples collected from septic tank, anoxic zone and aerobic zone were let to settle before analyzing for nitrate and total nitrogen. Dissolved oxygen (DO) was monitored continuously and remotely in the aerobic zone of the MBR by DO sensor (DO;Q45D/60, Analytical
Technology, Inc., USA), along with pH (Q45R/25R, pH monitor/ sensor, Analytical Technology, Inc., USA). Effluent total dissolved solids measured by specific conductance with gravimetric calibration varied over the period from 350 to $400 \mathrm{mg} / \mathrm{L}$.

\section{Model development}

The mathematical model developed in this work assumes the MBR configuration just described, including the addition of carbon substrate as ethanol and alkalinity as $\mathrm{CaCO}_{3}$, introduced to the anoxic and aerobic compartments of the reactor respectively. All biological processes taking place in the MBR are modeled based essentially on a modified ASM1 model, which includes formation and degradation of SMPs. Specifically, an extension of the ASM2d model version (Henze et al., 2000) published by International Wastewater Association, the ASM2dSMP model developed by Jiang et al. (2008) and modified by Mannina et al. to include physical components representing the MBR filtration process (Di Bella et al., 2008; Mannina et al., 2011b), was modified to include a saturation function term accounting for the effect of the concentration of alkalinity, $S_{A L K}$ on autotroph growth, originally present in ASM1 and ASM3, to model the addition of external alkalinity to the aerobic reactor. $S_{N 2}$ was also introduced to the model to maintain the model continuity, and model continuity was checked and verified as described in literature (Hauduc et al., 2010). Results indicate that model continuity errors are below $1.42 \times 10^{-14}$. In addition, relationships were added to describe alkalinity and external carbon addition, and oxygen transferred as a function of airflow rate. The resulting process rate expressions for the biological process components modeled are shown in Table A.1, with terms included to account for alkalinity addition highlighted. Control of mixing, or chamber recycling ratio, was taken into account in the model by introducing two new parameters, the mixing recycling ratios, $R_{m}$ during periods of mixing between aerobic and anoxic chambers, and $R_{r}$ otherwise, i.e. during rest.

A definition diagram for the dual-compartment MBR modeled is shown in Fig. 1, and used in obtaining a set of mass balance equations for each compartment, to model the dynamic variation of component concentrations in each compartment. Mass balance equations for the anoxic reactor are shown in Equations B.1-B.15, with variables as defined in Table 1 . All mass balance equations for the anoxic compartment are developed based on Eq. (1), where $Q_{r}$, is the recycling flow rate $\left[Q_{r}=\right.$ average daily flow $\times$ recycling ratio (either relaxation or mixing)] and the rate of generation of the component, $R$ is obtained from Table A. 2 using the process rates listed in Table A.1. The dashed lines were considered as the virtual boundaries for each compartment when obtaining the mass balance equations. A term to account for the addition of ethanol, as rapidly biodegradable chemical oxygen demand, rbCOD, is inserted into Eq. (B.2). Masses of dissolved oxygen received from the influent, carried out with the effluent, and transferred into wastewater by aeration were taken into account in Eq. (B.9) and (B.24). 
$\frac{d S_{x}^{a n}}{d t}=\frac{1}{V_{a n}} \cdot\left[Q_{i n} \cdot S_{x}^{i n}+Q_{r} \cdot S_{x}^{a r}-\left(Q_{r}+Q_{o u t}\right) \cdot S_{x}^{a n}\right]+[R]$

Mass balance equations for the aerobic reactor were obtained based on Fig. 1, again assuming the imaginary boundary of the aerobic reactor shown in the diagram, as shown in Equations B.16B.30. All the mass balance equations for aerobic compartment are based on Eq. (2), where the rate of generation of the component, $R$ is obtained from Table A.2 using the process rates listed in Table A.1.

$\frac{d S_{x}^{a r}}{d t}=\frac{1}{V_{a r}} \cdot\left[\left(Q_{r}+Q_{o u t}\right) \cdot S_{x}^{a r}-Q_{o u t} \cdot f \cdot S_{i}^{a r}-Q_{r} \cdot S_{x}^{a r}\right]+[R]$

A term to account for addition of alkalinity as $\mathrm{CaCO}_{3}$ is introduced into Eq. (B.29). Oxygen transfer rate (OTR) in Eq. (B.24) was modeled using the relationship between OTR and air flow rate based on equations found in the literature (Tchobanoglous et al., 2003) as shown in Eq. (3). biomass synthesis is obtained by oxidizing ammonia to nitrite and nitrate with oxygen acting as the electron acceptor (Henze et al., 2008; Tchobanoglous et al., 2003). Also, the carbon requirement of autotrophic nitrifying organisms for biomass synthesis is obtained from the dissolved $\mathrm{CO}_{2}$ in wastewater, and alkalinity in the aerobic reactor is consumed with their growth (Henze et al., 2008; Tchobanoglous et al., 2014, 2003). Specifically, $7.14 \mathrm{mg}$ alkalinity as $\mathrm{CaCO}_{3}$ are consumed per mg of ammonia as $\mathrm{N}$ converted, whereas only $3.57 \mathrm{mg}$ alkalinity as $\mathrm{CaCO}_{3}$ per $\mathrm{mg}$ of $\mathrm{NO}_{3}^{-}$as $\mathrm{N}$ are generated in denitrification. Therefore, a total consumption of alkalinity in the nitrification/denitrification process can be expected (Henze et al., 2008; Tchobanoglous et al., 2003), and if the influent alkalinity is insufficient, alkalinity may need to be added.

In the present work it was assumed that only soluble substrate passes the membrane, and that particulate components are retained in the reactor. Thus, the experimentally-measured effluent flow rate is used as a model input, and modeling of the flow as a function of time and filtration characteristics of the membrane module are not considered. Values of rbCOD were estimated

OTR $=\left[\frac{\alpha^{\text {OTR }} F^{\text {OTR }}\left(\beta^{\text {OTR }} C_{\bar{S}, T, H}^{\text {OTR }}-C_{L}^{\text {OTR }}\right)}{C_{S, 20}^{\text {OTR }}}\right] \frac{1}{1.024^{(20-T)}} \cdot Q_{a i r} \cdot E^{\text {OTR }} \cdot\left(\right.$ kg of $\left.\mathrm{O}_{2} / \mathrm{hr}\right)$

Under anoxic conditions heterotrophic organisms acquire their energy requirements by oxidizing rbCOD in the wastewater, and thereby reduce $\mathrm{NO}_{3}^{-}$to $\mathrm{N}_{2}$, where $\mathrm{NO}_{3}^{-}$acts as the electron acceptor in the absence of oxygen (i.e. at low DO concentrations relative to the concentration of $\mathrm{NO}_{3}^{-}$). Therefore, the oxidation-reduction potential (ORP) of the wastewater can be identified as the main factor affecting the denitrification process in the anoxic reactor. Previous study on ORP variations with respect to rbCOD and DO under anoxic conditions have shown that ORP is reduced as rbCOD increases, and ORP increases as DO increases (Li and Irvin, 2007). Even though DO delivered to the anoxic compartment through internal recycling cannot be readily controlled, ORP in the anoxic reactor can be controlled through the addition of ethanol (i.e. rbCOD) to maintain an ORP level favorable for efficient denitrification.

As a result of the biological mechanism just described, the rate of denitrification improves as ORP falls, such that ORP level should be maintained around the optimum value of $100-125 \mathrm{mV}$ (Fuerhacker et al., 2000; Lo et al., 1994), by controlling rbCOD. In particular, previous studies have shown that the addition of an external carbon source such as methanol, ethanol or acetate is effective in enhancing the denitrification process (Agathos and Reineke, 2003; Dalmau et al., 2013; Henze et al., 2008; Ivanov, 2011; Peng et al., 2007; Tchobanoglous et al., 2003). Ethanol and acetate can be considered as alternative electron donors which enhance the denitrification process, and denitrifying bacteria are dominant when $\mathrm{NO}_{3}^{-}$and ethanol are present in the medium. In this work to develop an advanced oxidation-based net-zero water DPR process, it was desired to add a carbon source that was both (a) non-toxic, to avoid any issue with the finished drinking water, and (b) non-saline, to avoid unnecessary salinity increase in the absence of reverse osmosis treatment. Hence ethanol was chosen as the carbon source.

In the aerobic compartment, DO concentration must be maintained at an optimum level for efficient nitrification, because the energy requirement of autotrophic nitrifying organisms for assuming a ratio calculated based on average COD in the MBR prior to, and after, filtration through the flat membrane module of the MBR. Use of such a ratio has been reported successful in previous work (Hai et al., 2014). This rbCOD to COD ratio was calculated as 0.48 based on equations found in literature (Tchobanoglous et al., 2014, 2003). Comparing the calculated ratio with the values found in literature, rbCOD to COD ratios from 0.08 to 0.64 have been reported for wastewater of different treatment plants (Koch et al., 2000). It should be noted that this ratio could be higher in the present work due to the addition of ethanol. The amount of COD added to the anoxic chamber as ethanol was calculated based on the theoretical COD of ethanol (2.09 $\mathrm{mg} \mathrm{COD} / \mathrm{mg}$ ethanol).

\section{Software implementation and calibration}

Software implementation of the model was carried out in Matlab Simulink ver. 2014a ("Autonomous Net-Zero Water Project," 2017). Simulation using the automatic solver was carried out with a fixed step size of $30 \mathrm{~s}$, because the septic tank pump turns on for $30 \mathrm{~s}$ every $3 \mathrm{~h}$. The influent wastewater characteristics, MBR timer schedules, the monitored influent flow pattern over the period, and model parameter values are passed to Matlab workspace through a set of Microsoft excel files. Effluent water characteristics were also passed to Matlab workspace together with the influent wastewater characteristics in order to calibrate the model parameters. Final simulation results are output to a folder in pdf or/and jpeg format, including a Microsoft Excel file containing model parameters and initial conditions used for the simulation.

The model was calibrated and validated with the data taken from the pilot MBR. It has been suggested that such biological model predictions based only on influent and effluent wastewater characteristics may not always be valid, whereas model results based on intermediate substrate concentrations in the aerobic and anoxic stages provide a more reliable indication of system kinetics (Tchobanoglous et al., 2003). Therefore, in this work kinetic parameters were calibrated based on water quality data obtained 
Table 2

Comparison between calibrated parameters and parameters found in previous works.

\begin{tabular}{|c|c|c|c|c|c|c|}
\hline Parameter & Units & Calibrated Value & (Henze et al., 2008) & (Baek et al., 2009) & (Keskitalo et al., 2010) & (Mannina et al., 2011b) \\
\hline$\mu_{H}$ & day $^{-1}$ & 5 & 6.0 & 6.9 & 8.4 & 6.002 \\
\hline$\mu_{A}$ & day $^{-1}$ & 1.0 & 0.8 & 0.67 & - & 0.606 \\
\hline$b_{H}$ & day $^{-1}$ & 0.40 & 0.22 & 0.22 & 0.744 & 0.99 \\
\hline$b_{A}$ & day $^{-1}$ & 0.05 & 0.048 & 0.048 & - & 0.099 \\
\hline$Y_{H}$ & $g C O D / g C O D$ & 0.67 & 0.67 & 0.69 & 0.72 & 0.57 \\
\hline$Y_{A}$ & $g C O D / g N$ & 0.07 & 0.24 & 0.28 & - & 0.21 \\
\hline$K_{a}$ & $m^{3} /(g C O D \cdot d a y)$ & 0.04 & 0.08 & 0.082 & 0.16 & 0.102 \\
\hline$K_{h}$ & $g C O D /(g C O D \cdot d a y)$ & 1.5 & 3 & 3 & 4.5 & 4.095 \\
\hline$K_{h, B A P}$ & $g C O D /(g C O D \cdot$ day $)$ & 0.1 & - & - & - & 0.0112 \\
\hline$f_{B A P}$ & - & 0.223 & - & - & - & 0.222 \\
\hline$K_{h, U A P}$ & $g C O D /(g C O D \cdot d a y)$ & 0.1 & - & - & - & 0.1285 \\
\hline$f_{U A P}$ & - & 0.235 & - & - & - & 0.212 \\
\hline$K_{s}$ & $m g / l$ & 20 & 20 & 20.3 & 15 & 76.94 \\
\hline$K_{\mathrm{OH}}$ & $m g / l$ & 0.015 & 0.2 & 0.19 & 0.2 & 0.015 \\
\hline$K_{N O}$ & $m g / l$ & 0.5 & 0.5 & 0.45 & - & 0.136 \\
\hline$K_{N H}$ & $m g / l$ & 0.4 & 1 & 0.94 & 0.1 & 0.964 \\
\hline$K_{O A}$ & $\mathrm{mg} / \mathrm{l}$ & 0.4 & 0.4 & 0.1 & - & 1.14 \\
\hline$K_{X}$ & $g C O D / g C O D$ & 0.045 & 0.03 & 0.04 & 0.09 & 0.0345 \\
\hline$\eta_{g}$ & - & 0.9 & 0.9 & 0.9 & - & 0.892 \\
\hline$\eta_{h}$ & - & 0.2 & 0.4 & 0.4 & - & 0.258 \\
\hline$i_{x b}$ & $g N / g C O D$ & 0.1 & 0.086 & 0.088 & 0.05 & 0.0401 \\
\hline$i_{x p}$ & $\mathrm{gN} / \mathrm{gCOD}$ & 0.03 & 0.06 & 0.06 & 0.035 & 0.0876 \\
\hline$f_{p}$ & - & 0.15 & 0.08 & 0.08 & 0.08 & 0.193 \\
\hline$f_{b}$ & - & 0.001 & 0.005 & 0.005 & - & 0.006 \\
\hline$f$ & - & 0.82 & - & - & - & 0.82 \\
\hline$R_{r}$ & - & 1.5 & - & - & - & - \\
\hline$R_{m}$ & - & 3 & - & - & - & - \\
\hline
\end{tabular}

from both the aerobic and anoxic zones.

Coarse calibration of model parameters was achieved by carrying out simulations with different parameter sets, assessing the model efficiency, and automatically adjusting parameter values while retaining the most efficient parameter set. When selecting a parameter set, one parameter at a time was varied within the broadest range found in the literature, and the process was repeated according to the calibration protocol described in (Mannina et al., 2011a). In this study 28 parameters were calibrated based on four model outputs and 9 input time series. Calibrated parameters were then manually fine-tuned to achieve a visual fit to the measured water quality characteristics.

\section{Results and discussion}

The final calibrated parameter values, in comparison with the calibrated parameters reported in previous work are summarized in Table 2.

Comparing calibrated parameters with those reported in previous work, the maximum specific growth rate $\left(\mu_{H}\right)$ for heterotrophs in the modeled system, 5/d, appears slightly low. However, the rate of growth depends significantly on the nature of the wastewater being treated (Henze et al., 2000) and the reactor configuration. In terms of influent characteristics, in the work of Mannina and co-workers (Di Bella et al., 2008; Mannina et al., 2011b), the influent was unsettled, primarily domestic wastewater with an average COD of $510 \mathrm{mg} / \mathrm{L}$, whereas the influent in this work was settled domestic wastewater in a NZW system with $192 \mathrm{mg} / \mathrm{L}$ average COD, augmented by $228 \mathrm{mg} / \mathrm{L}$ of COD added as ethanol. Furthermore, the heterotrophic biomass concentration in this study was in the lower range (580-810 mg-COD/L) compared with that observed by Baek et al. (2009) (298-4415 mg-COD/L), perhaps due to the low heterotrophic growth rate.

In terms of reactor configuration, reactors of Baek et al. (2009) and Mannina et al. (2011b) were single-compartment, simultaneous nitrification/denitrification reactor configurations, whereas the MBR modeled in this work is a dual compartment MBR, equally divided by perforated baffle. Hence, heterotroph growth was limited in the reactor modeled in this work by both substrate and DO. Also, a high heterotrophic growth rate $\left(8.4 \mathrm{~d}^{-1}\right)$ has been reported when the DO concentration is maintained at a relatively high level (3-6 mg/L) (Koch et al., 2000). In this work only the aerobic zone was aerated, and the master control panel was set on a timer to prevent excess aeration, limiting the DO. In fact, DO probe readings in the aerobic zone indicated anoxic conditions in the aerobic zone every $6 \mathrm{~h}$ when aeration was shut off, in agreement with literature (Capodici et al., 2015). In contrast, the pilot plant modeled in comparison work (Baek et al., 2009; Mannina et al., 2011b) consisted of single compartment where the aerator module is installed, and the aerator was run continuously at a constant air flow of $3 \mathrm{~m}^{3} / \mathrm{h}$. In fact, the authors report formation of an anoxic zone, resulting in inferior agreement (high COD) with model results during first 2 weeks due to lack of anoxic zone representation in their model. Agreement improved subsequently due to anoxic zone reduction by periodic anoxic sludge wasting.

Nitrate and total nitrogen concentrations were predicted well within the period of the experiment, as shown in Figs. 2 and 3, respectively. From the results, it is clear that sufficient denitrification cannot be achieved in this influent without addition of external carbon. Without addition of external carbon, the average effluent nitrate concentration reached $\sim 40 \mathrm{mg} / \mathrm{L}$, comparable with previous work (Mannina et al., 2011b). Dalmau et al. (2013) also emphasized that the rate of external carbon addition is strongly influential in terms of efficient nutrient removal. However in the simulated TN results, as shown in Fig. 3, some TN spikes, representing ammonia, were not observed in measured data. This difference is attributed to the high ammonium uptake rates reportedly observed in MBRs (Fenu et al., 2010; Manser et al., 2006), not accounted for in the model. Model and experimental results confirm previous findings that nitrogen removal efficiency increases with the COD to nitrogen $(\mathrm{COD} / \mathrm{N})$ ratio (Mannina et al., 2016; Peng et al., 2007). According to literature a minimum $\mathrm{C} / \mathrm{N}$ ratio of $3.5-4.5 \mathrm{~g}-\mathrm{COD} / \mathrm{g}-\mathrm{N}$ is required 

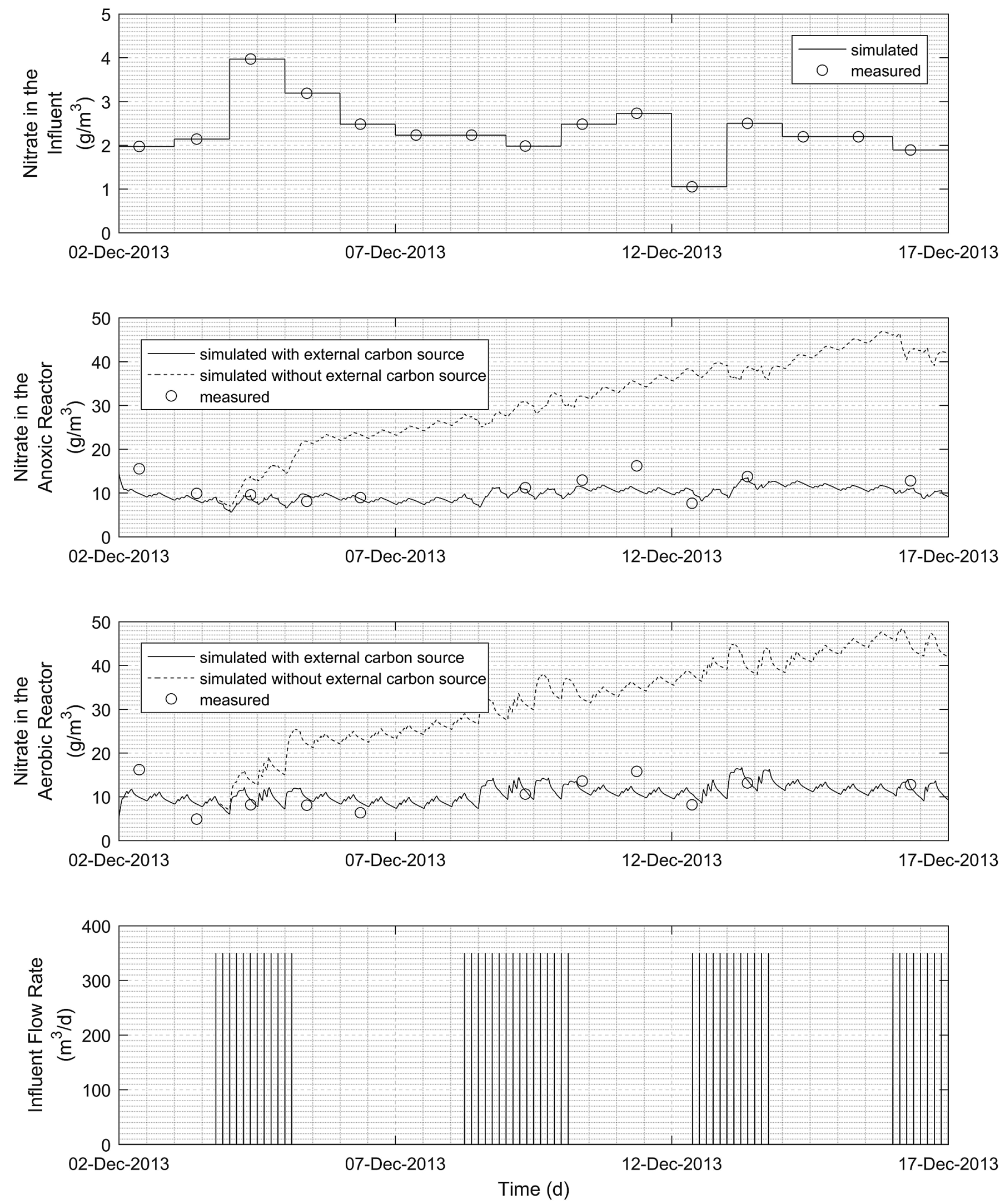

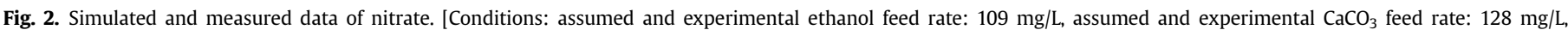
measured temperature: $24-26.7^{\circ} \mathrm{C}$ ]. 

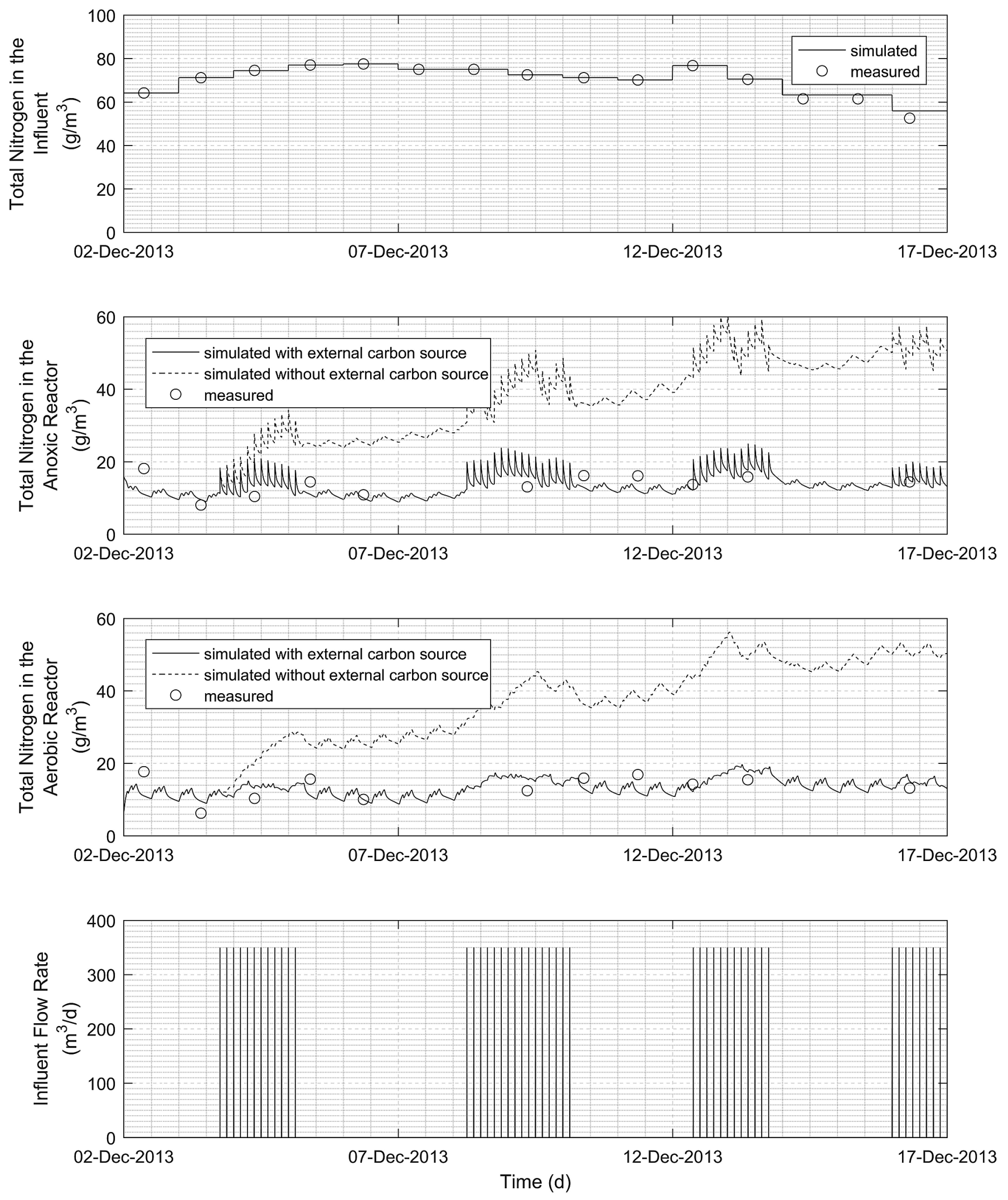

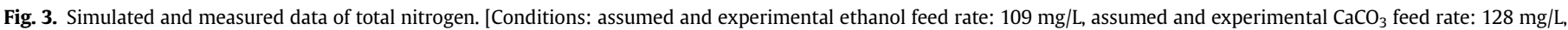
measured temperature: $24-26.7^{\circ} \mathrm{C}$. 

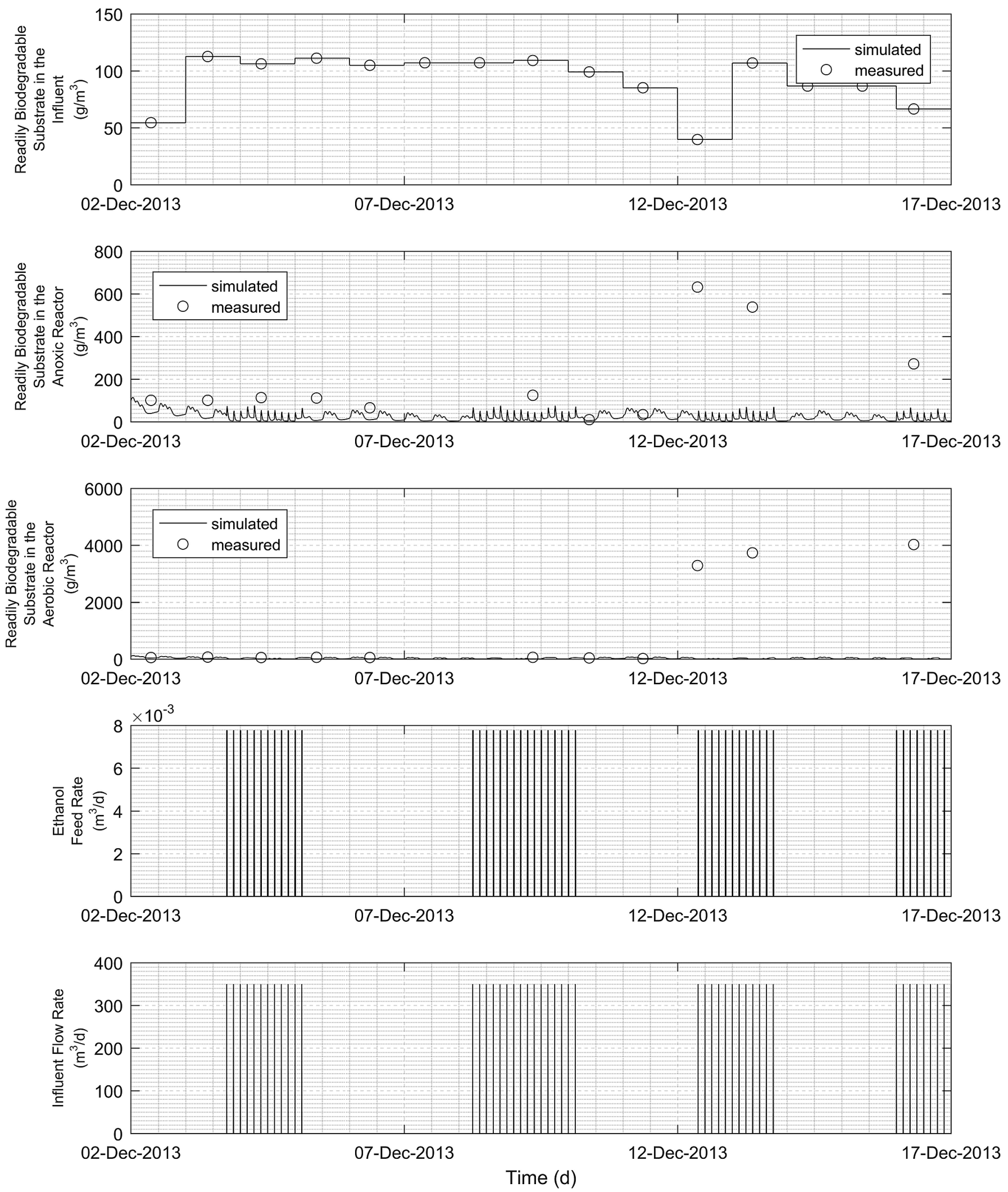

Fig. 4. Simulated and measured data of readily biodegradable substrate. [Conditions: ethanol feed rate: $109 \mathrm{mg} / \mathrm{L}, \mathrm{CaCO}$ feed rate: $128 \mathrm{mg} / \mathrm{L}$, temperature: $24-26.7{ }^{\circ} \mathrm{C}$.

and proposed a $\mathrm{C} / \mathrm{N}$ ratio of $6-11 \mathrm{~g}-\mathrm{COD} / \mathrm{g}-\mathrm{N}$ to achieve good nitrogen removal (Sun et al., 2010). In particular, experimental results show $80 \%$ total nitrogen removal from the influent wastewater to the settled mixed liquor of the aerobic zone, with external carbon source addition at a $\mathrm{COD} / \mathrm{N}$ ratio of $\sim 6$. Total nitrogen removal across the whole MBR (i.e. from septic tank to dosing tank which collects the filtered effluent) was calculated as $87.4 \%$. Based on the model results, only $50 \%$ nitrogen removal can be achieved at a COD/ 

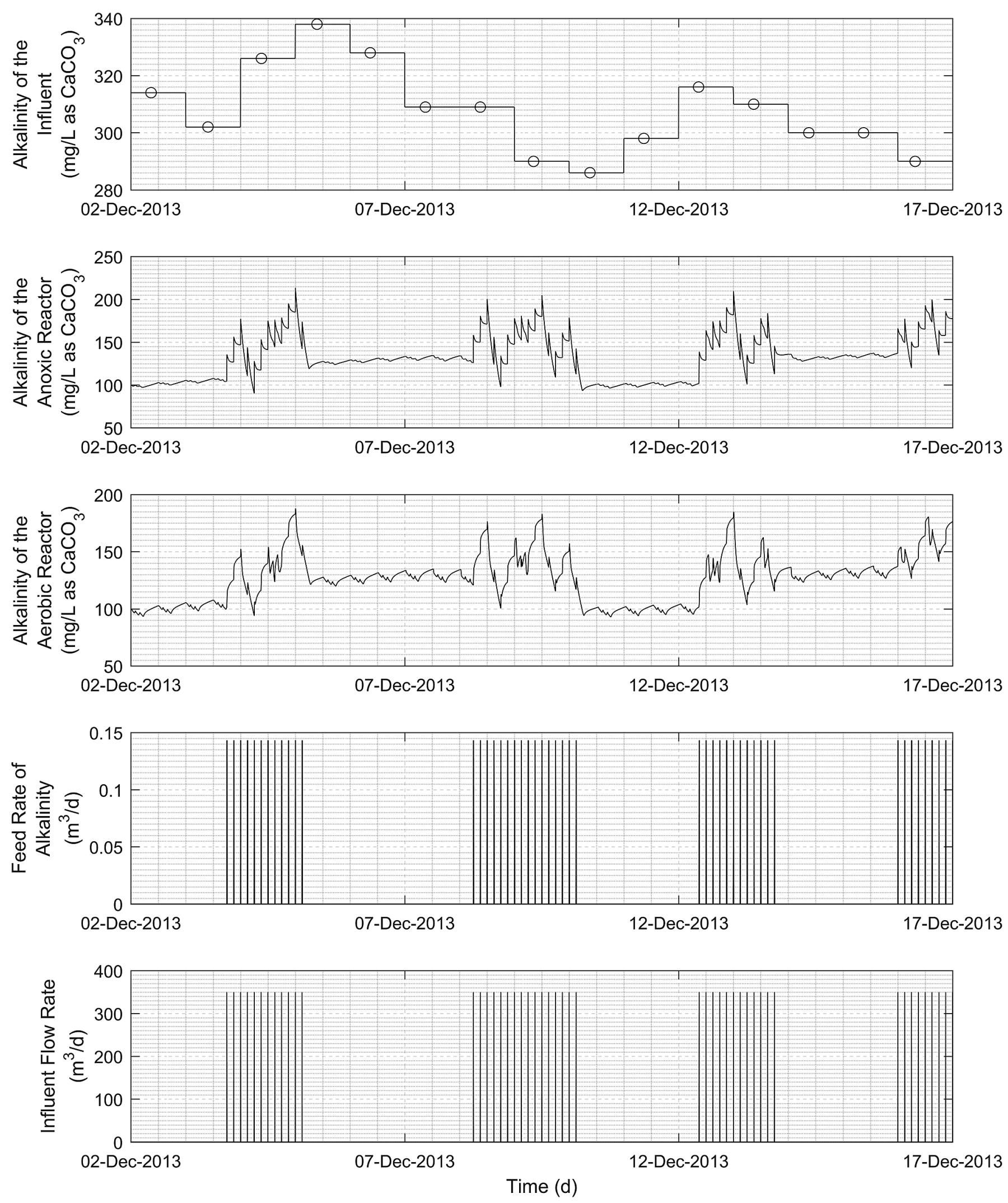

Fig. 5. Simulated alkalinity. [Conditions: ethanol feed rate: $109 \mathrm{mg} / \mathrm{L}, \mathrm{CaCO}_{3}$ feed rate: $128 \mathrm{mg} / \mathrm{L}$, temperature: $24-26.7^{\circ} \mathrm{C}$ ].

$\mathrm{N}$ ratio of 2.74 , without external carbon addition.

In terms of readily biodegradable substrate, as shown in Fig. 4, unexpectedly high COD values were measured in samples from both anoxic and aerobic zones of the MBR after $12^{\text {th }}$ December 2013. Such high COD in the MBR would have been expected to have significant effect on nitrate and total nitrogen. However, nitrate and 

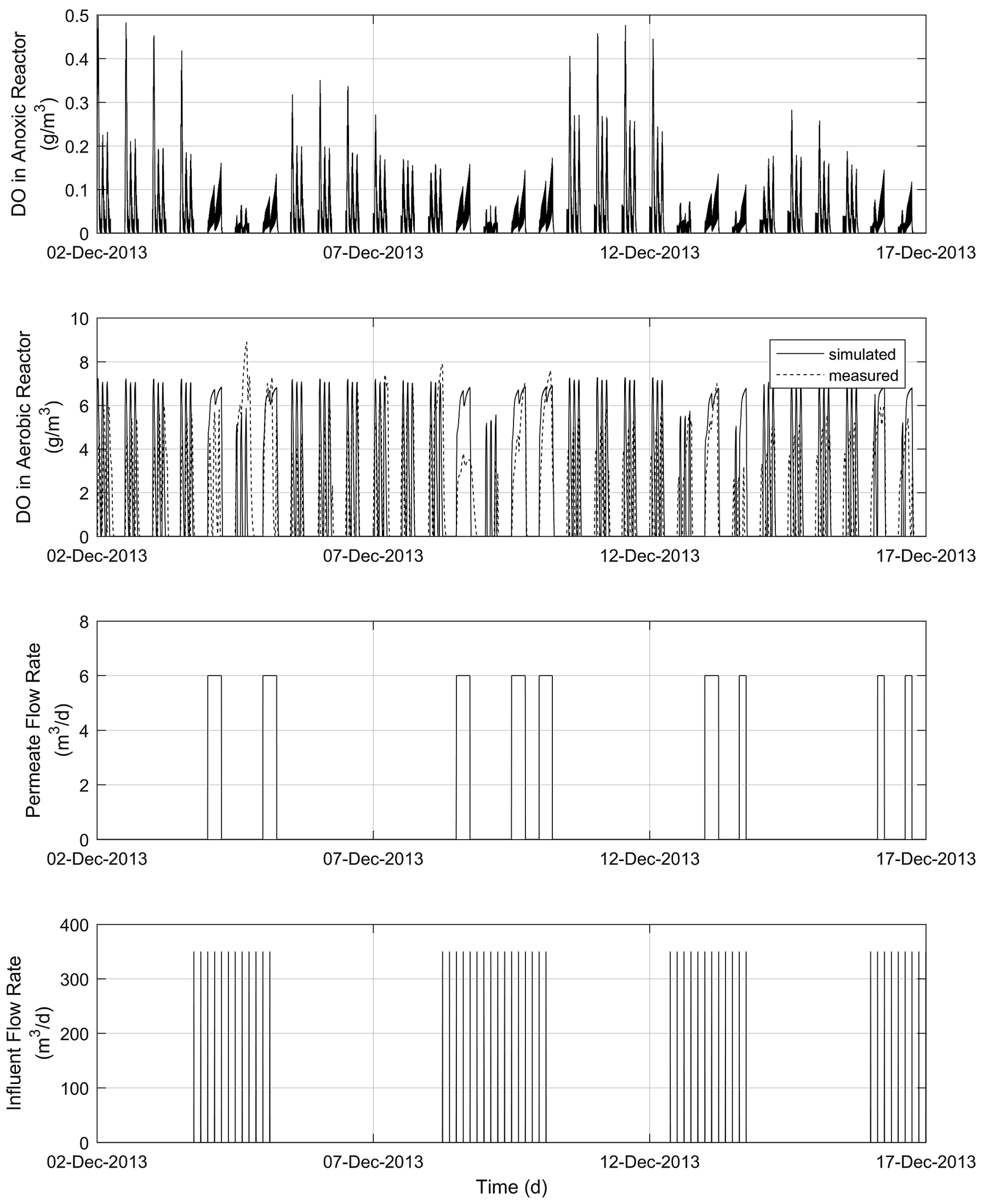

Fig. 6. Simulated and measured data of dissolved oxygen. [Conditions: ethanol feed rate: $109 \mathrm{mg} / \mathrm{L}, \mathrm{CaCO}_{3}$ feed rate: $128 \mathrm{mg} / \mathrm{L}$, temperature: $24-26.7{ }^{\circ} \mathrm{C}$. 
Table 3

External carbon source feed rates at different aeration settings.

\begin{tabular}{|c|c|c|c|c|c|}
\hline Run & Blower ON (min) & Blower OFF (min) & Ethanol feed $(\mathrm{mg} / \mathrm{L})$ & Anoxic DO (mg/L) & Aerobic DO $(\mathrm{mg} / \mathrm{L})$ \\
\hline 1 & 15 & 105 & 88 & 0.0143 & 1.4609 \\
\hline 2 & 30 & 90 & 109 & 0.0224 & 1.8513 \\
\hline 3 & 45 & 75 & 131 & 0.0302 & 2.2208 \\
\hline 4 & 60 & 60 & 160 & 0.0409 & 2.6532 \\
\hline 5 & 75 & 45 & 186 & 0.0524 & 3.0655 \\
\hline 6 & 90 & 30 & 206 & 0.0645 & 3.3625 \\
\hline 7 & 105 & 15 & 238 & 0.0819 & 3.5904 \\
\hline
\end{tabular}

total nitrogen did not seem to be affected. Therefore, these high COD readings were attributed to the possible presence of small organic particulates in the samples, which were highly diluted for measurement.

Simulated "available alkalinity" shown in Fig. 5 represents an estimate of the alkalinity available to the microorganisms. The available alkalinity is the alkalinity present in the MBR before precipitation with available hardness ions and before any volatilization as $\mathrm{CO}_{2}$. The equilibrium levels for both of these reactions, determined by equilibration with atmospheric $\mathrm{CO}_{2}$ through aeration, are not accounted for in the model. Hence, modeled alkalinity available to the microorganisms seems to stabilize around $130 \mathrm{mg} / \mathrm{L}$ as $\mathrm{CaCO}_{3}$, whereas measured alkalinity dissolved in the MBR effluent averaged $78.5 \mathrm{mg} / \mathrm{L}$ as $\mathrm{CaCO}_{3}$. In fact, the alkalinity was fed to the $\mathrm{MBR}$ as $\mathrm{CaCO}_{3}$ at a rate of $128 \mathrm{mg} / \mathrm{L}$, and based on subsequent minerals analysis in the MBR effluent (Gassie et al., 2016), sufficient calcium was present for precipitation of excess alkalinity not consumed microbiologically.

Predicted DO concentrations shown in Fig. 6 align well with the measured DO. In fact, it has been reported that the oxygen uptake rate reflects several different model characteristics, and thus provides meaningful data for model calibration (Tchobanoglous et al., 2003). Further, the oxygen uptake rate directly impacts the DO in the aerobic zone, which has a high positive effect on the accuracy of the model predictions.

Because DO has been identified as an important parameter in model calibration (Tchobanoglous et al., 2003), the external carbon source requirement to maintain total nitrogen concentration at $\sim 13.4 \mathrm{mg} / \mathrm{L}$ was determined by changing the amount of air supplied to the MBR. The concentration $13.4 \mathrm{mg} / \mathrm{L}$ was selected because it was the average of the measured data over the period of experiment. The external carbon required to maintain this effluent total nitrogen level at different DO concentrations in aerobic tank was assessed with the model by varying the MBR aeration blower schedule during the relaxation cycle, assuming the different timer settings listed in Table 3. Optimal ethanol feed rates were then determined to achieve $\sim 13.4 \mathrm{mg} / \mathrm{L}$ effluent TN.

As shown in Fig. 7, aeration for at least 30 min during $120 \mathrm{~min}$ cycle, equivalent to $104 \mathrm{~m}^{3}$ air/d per $1 \mathrm{~m}^{3} / \mathrm{d}$ average influent flow rate, is required to keep the effluent 4-d ammonia running average concentration below $1.5 \mathrm{mg} / \mathrm{L}$ in the aerobic reactor. A 4-d running average was assessed because both simulated and measured
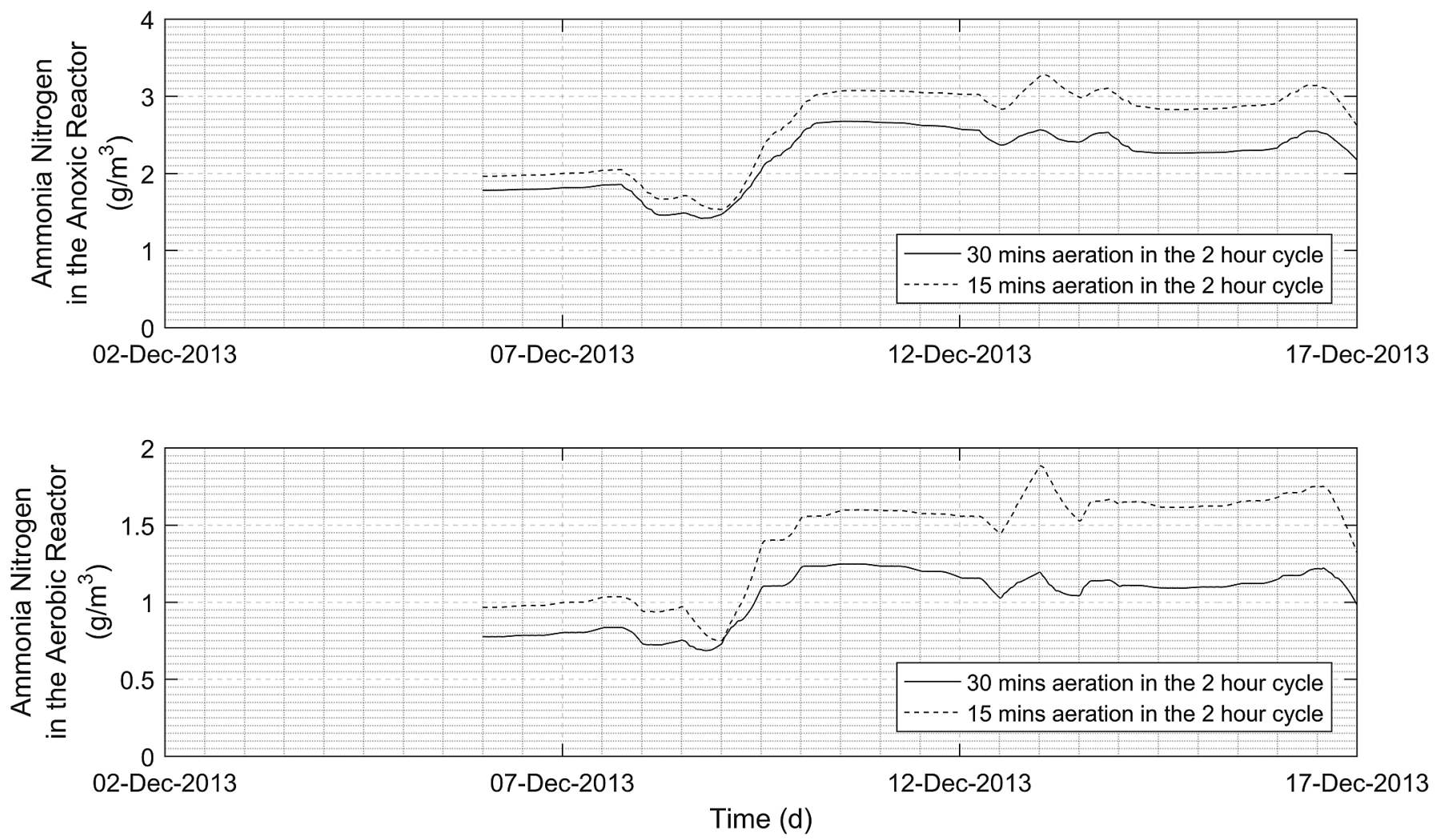

Fig. 7. Effect of aeration on effluent ammonia concentration. [Conditions: ethanol feed rate: $109 \mathrm{mg} / \mathrm{L}, \mathrm{CaCO}_{3}$ feed rate: $128 \mathrm{mg} / \mathrm{L}$ ]. 


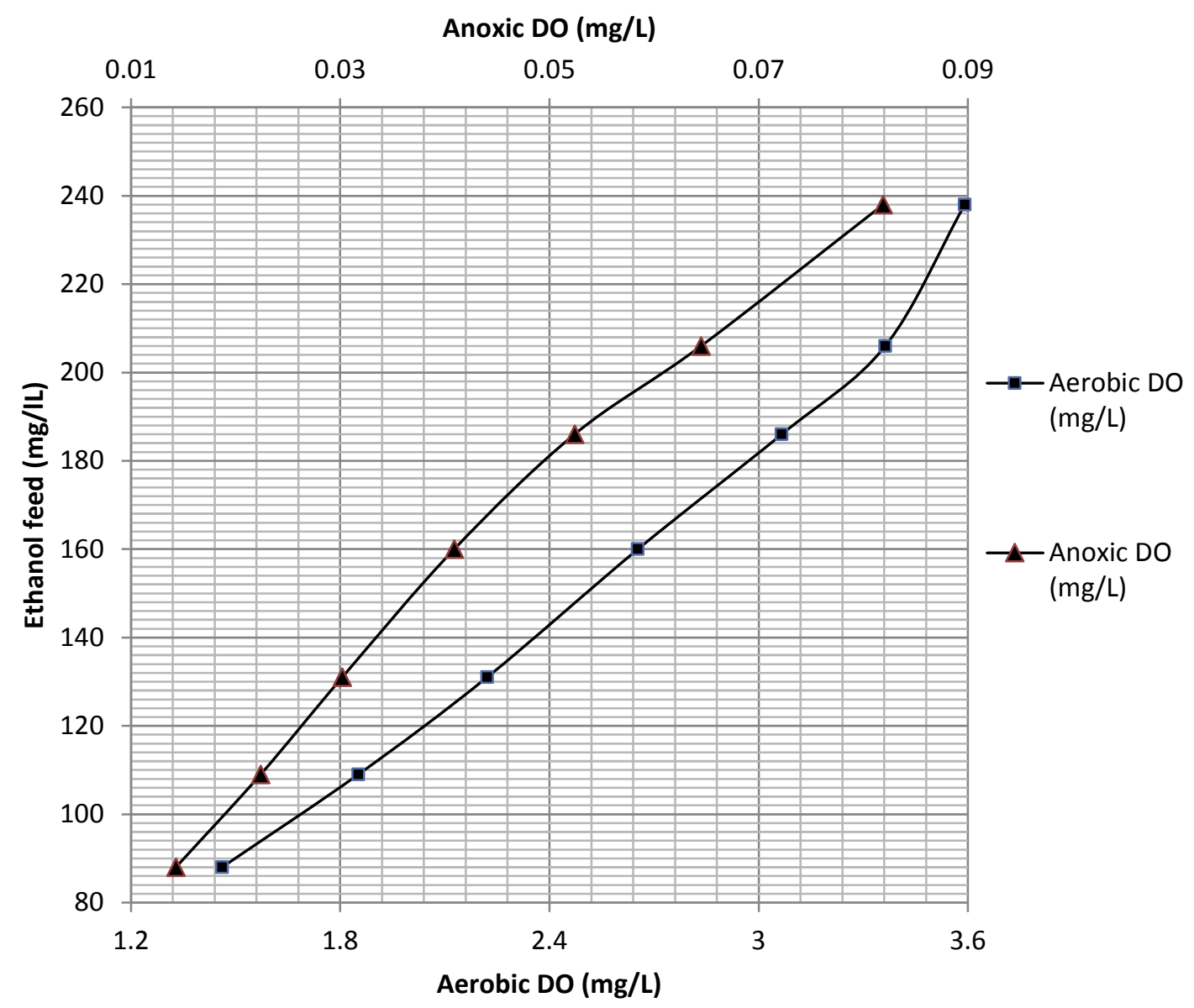

Fig. 8. Predicted ethanol feed rate vs DO concentration at different aeration settings. [Conditions: average effluent TN $=\sim 13.4 \mathrm{mg} / \mathrm{L}$ ].

concentrations of model parameters show a cyclic behavior with cycle duration of $4 \mathrm{~d}$. A threshold value of $1.5 \mathrm{mg} / \mathrm{L}$ effluent ammonia, 4-day running average, was assumed as a maximum, based on the World Health Organization threshold value to avoid ammonia odor (World Health Organization, 2008). The average aeration rate is high due to the design of this onsite system for minimal maintenance and high peak capacity.

Based on the model results, the anoxic DO in the two-chamber, mixed MBR is affected by aeration, and the required ethanol feed rate increases as the anoxic DO increases. It was reported that the optimum ORP for denitrification is $100-125 \mathrm{mV}$, and that COD can maintain ORP within favorable ranges for denitrification (Fuerhacker et al., 2000; Lo et al., 1994). Further it has been reported that ORP is an important parameter in system management which impacts denitrification efficiency and is strongly affected by DO (Capodici et al., 2015). Therefore, the external carbon source required to maintain these conditions in the anoxic reactors when aerobic recycling is taken place is plotted in Fig. 8. Points in Fig. 8 correspond to the aeration settings shown in Table 3 .

In addition to the aeration rate, the recycling ratio is an important factor in determining external carbon source requirement Recycling ratio controls substrate, nutrients, and DO recycled in between the aerobic and anoxic zones. As shown in Table 4, while DO in the aerobic zone decreases as a result of increasing the recycling ratio, DO in the anoxic zone is increased, increasing the demand for external carbon to maintain favorable ORP levels for denitrification. Thus, based on model results, the system can maintain effluent TN at $\sim 13.4 \mathrm{mg} / \mathrm{L}$ when external carbon source feed is increased accordingly.

Increased demand for external carbon source as the DO in the anoxic zone is increased can be seen in Table 4 and Fig. 9. It should be noted that the demand for external carbon for a particular DO concentration in the anoxic zone resulting from an increase in the recycling ratio is much lower than that for the same anoxic DO concentration resulting from an increase in the aeration rate, because recycling delivers rbCOD as well as DO to the anoxic zone.

Table 4

External carbon source feed rates at different recycling ratios.

\begin{tabular}{|c|c|c|c|c|c|}
\hline Run & Recycling ratio (rest mode) & Recycling ratio (mixing mode) & Ethanol feed (mg/L) & Anoxic DO (mg/L) & Aerobic DO (mg/L) \\
\hline 1 & 1.5 & 3 & 109 & 0.0224 & 1.8513 \\
\hline 2 & 2 & 4 & 115 & 0.0446 & 1.8163 \\
\hline 3 & 2.5 & 5 & 121 & 0.0883 & 1.7957 \\
\hline 4 & 3 & 6 & 126 & 0.1381 & 1.7836 \\
\hline 5 & 3.5 & 7 & 131 & 0.2056 & 1.7773 \\
\hline 6 & 4 & 8 & 137 & 0.2813 & 1.7749 \\
\hline
\end{tabular}




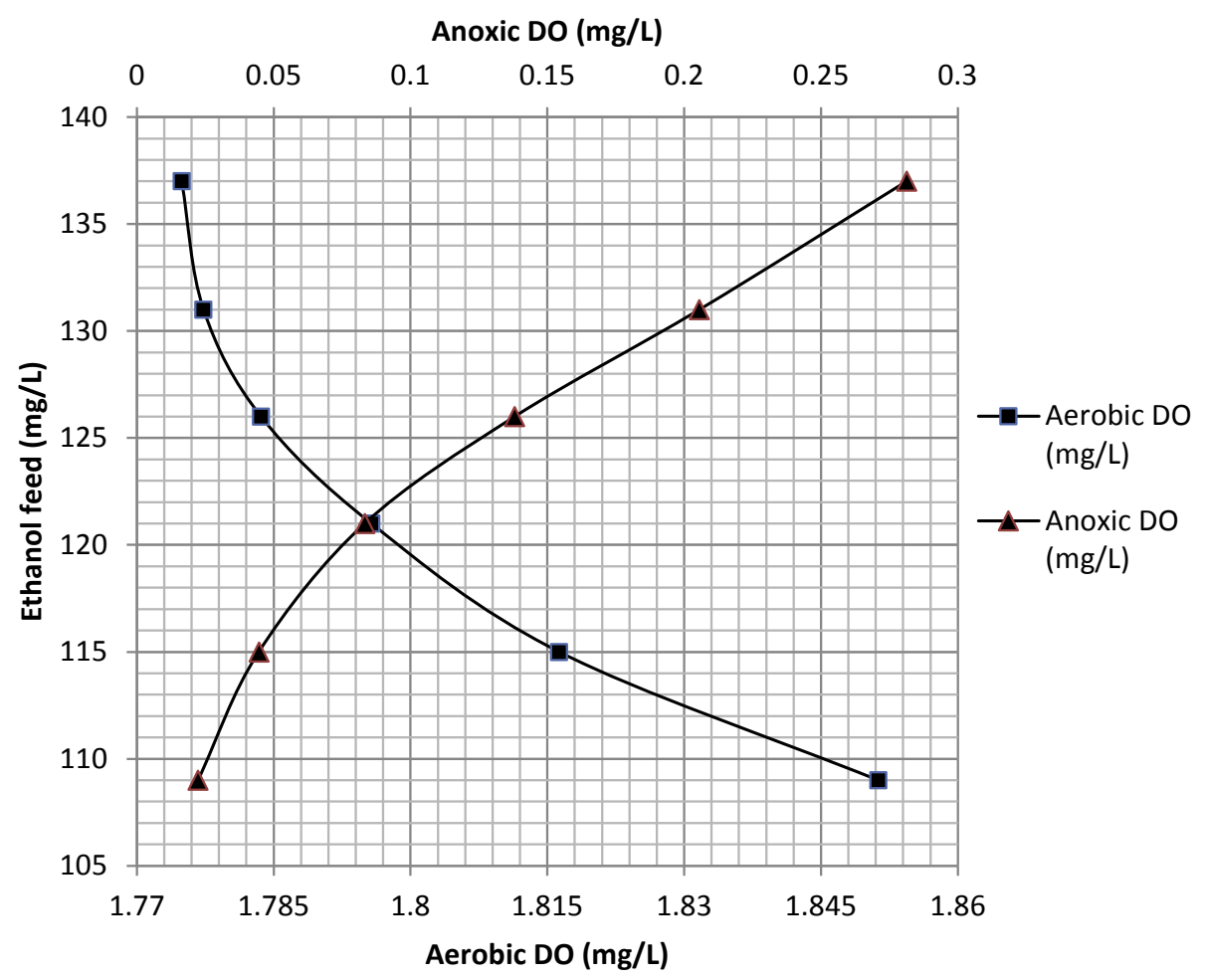

Fig. 9. Predicted ethanol feed rate vs DO concentration at different recycling ratios. [Conditions: average effluent TN $=\sim 13.4 \mathrm{mg} / \mathrm{L}$ ].

Ultimately it was found that an average effluent TN of $\sim 13.4 \mathrm{mg} /$ $\mathrm{L}$ can be maintained in the modeled system with slightly less external carbon addition than would typically be predicted. According to the general guidance found in literature, a COD: TKN ratio should be maintained at 8:1 to achieve efficient denitrification (Grady et al., 1999), though demand for COD depends on reactor configuration and operating conditions (Tchobanoglous et al., 2003). Accordingly, in the modeled system, $248 \mathrm{mg} / \mathrm{L}$ of COD, equivalent to $119 \mathrm{mg} / \mathrm{L}$ of ethanol, would be required to denitrify influent wastewater with $68 \mathrm{mg} / \mathrm{L}$ of TKN and $192 \mathrm{mg} / \mathrm{L}$ of COD to maintain average effluent TN at $13.4 \mathrm{mg} / \mathrm{L}$. However, model and experimental results indicate a requirement of only $109 \mathrm{mg} / \mathrm{L}$ ethanol.

\section{Conclusions and recommendations}

A two-chamber, nitrifying/denitrifying, $500 \mathrm{gal} / \mathrm{d}$ MBR installed as part of a net-zero water ( $85 \%$ recycle) DPR system was modeled to account for external carbon and alkalinity addition, variable aeration schedule, and mixing between separate aerobic and anoxic zones, and calibrated with field data. The following conclusions are made regarding the external carbon source requirement and associated control parameters, based on model results indicating the effect of aeration schedule and recycling ratio on anoxic zone DO and the resulting effect on effluent TN.

- The modified ASM-based model presented can be used to describe the performance of an onsite aerobic nitrifying/denitrifying SMBR with variable aeration schedule, variable aerobic/ anoxic mixing, and external carbon and alkalinity addition.

- The external carbon requirement for denitrification increases with increased recycling ratio, as a result of increased DO in the anoxic zone, and this requirement can be optimized by varying the aeration schedule and recycling ratio.
- In simultaneous nitrification/denitrification MBRs, aeration is a critical control parameter in terms of achieving sufficient nitrification and denitrification with minimal external carbon addition. The requirement for external carbon addition can be reduced by lowering the aeration rate, subject to the maximum tolerable ammonia concentration in the effluent. Model results for the present reactor indicate that 30 min aeration during a $2 \mathrm{~h}$ cycle, equivalent to $104 \mathrm{~m}^{3}$ air/d per $1 \mathrm{~m}^{3} / \mathrm{d}$ average influent flow rate, was optimal to achieve an average $13.4 \mathrm{mg} / \mathrm{L}$ of effluent TN with minimum external carbon addition.

- The recycling ratio should be controlled carefully to maintain sufficient nutrient recirculation and favorable ORP for denitrification. The optimum recycling ratio to achieve an average $13.4 \mathrm{mg} / \mathrm{L}$ of effluent TN with minimum external carbon source was found for the modeled reactor as 1.5 and 3 during the rest and mixing periods respectively.

- The external carbon feed rate can be controlled effectively by monitoring ORP, which reflects the effects of both aeration and recycling ratio, and can be maintained at favorable levels through adjustment of the carbon feed rate.

- Ultimately, the simultaneous effect of both aeration schedule and recycling ratio should be taken into account in optimizing the carbon source requirement in two chamber intermittently aerated MBRs. The model presented here can be used to assess the interactive effects of aeration schedule and recycle ratio in optimizing the external carbon feed rate to achieve a given effluent TN concentration.

\section{Acknowledgements}

This work was supported in large part by the US National Science Foundation (EFRI-SEED Award 1038257), the U.S. Environmental Protection Agency, the University of Miami, and Engineered Control Systems, Inc. BioMicrobics, Inc. and Wastewater Control 
Systems, Inc. are also thanked for in-kind contributions to system construction. The authors would also like to thank Mark Repasky for input to system design and for system installation. In addition, Tingting Wu, Lucien Gassie, and Guanghui Wang are thanked for carrying out the data collection campaign, and numerous students and interns of the net-zero water team are gratefully acknowledged for help with laboratory experiments.

\section{Appendix A}

$$
\begin{aligned}
\frac{d S_{s}^{a n}}{d t}= & \frac{1}{V_{a n}} \cdot\left[Q_{\text {in }} \cdot S_{s}^{i n}+Q_{r} \cdot S_{s}^{a r}+q_{\text {eth }}^{a d d} \cdot S_{\text {eth }}^{a d d}-\left(Q_{r}+Q_{\text {out }}\right) \cdot S_{s}^{a n}\right] \\
& +\left[-\frac{1}{Y_{H}} \cdot \rho_{1}-\frac{1}{Y_{H}} \cdot \rho_{2}+\rho_{7}+\left(1-f_{b}\right) \cdot\left(\rho_{9}+\rho_{10}+\rho_{11}+\rho_{12}\right)\right]
\end{aligned}
$$

$$
\begin{aligned}
\frac{d X_{i}^{a n}}{d t}= & \frac{1}{V_{a n}} \cdot\left[Q_{i n} \cdot X_{i}^{i n}+Q_{r} \cdot X_{i}^{a r}-\left(Q_{r}+Q_{o u t}\right) \cdot X_{i}^{a n}\right] \\
& +\left[f_{p} \cdot\left(\rho_{4}+\rho_{5}\right)\right]
\end{aligned}
$$

\begin{tabular}{|c|c|c|}
\hline$j$ & Process modeled, $j$ & Process rate equation \\
\hline 1 & Rate of aerobic growth of heterotrophs, $\rho_{1}$ & $\rho_{1}=\mu_{H} \cdot \frac{S_{s}}{S_{s}+K_{s}} \cdot \frac{S_{O}}{S_{O}+K_{O H}} \cdot \frac{S_{A L K}}{S_{A L K}+K_{A L K}} \cdot \frac{S_{N H}}{S_{N H}+K_{N H}} \cdot X_{B H}$ \\
\hline 2 & Rate of anoxic growth of heterotrophs, $\rho_{2}$ & $\rho_{2}=\mu_{H} \cdot \frac{S_{s}}{S_{s}+K_{s}} \cdot \frac{K_{O H}}{K_{O H}+S_{0}} \cdot \frac{S_{N O}}{S_{N O}+K_{N O}} \cdot \frac{S_{A L K}}{S_{A L K}+K_{A L K}} \cdot \frac{S_{N H}}{S_{N H}+K_{N H}} \cdot X_{B H}$ \\
\hline 3 & Rate of aerobic growth of autotrophs, $\rho_{3}$ & $\rho_{3}=\mu_{A} \cdot \frac{S_{N H}}{S_{N H}+K_{N H}} \cdot \frac{S_{O}}{S_{0}+K_{O A}} \cdot \frac{S_{A L K}}{S_{A L K}+K_{A L K}} \cdot X_{B A}$ \\
\hline 4 & Rate of lysis of heterotrophs, $\rho_{4}$ & $\rho_{4}=b_{H} \cdot X_{B H}$ \\
\hline 5 & Rate of lysis of autotrophs, $\rho_{5}$ & $\rho_{5}=b_{A} \cdot X_{B A}$ \\
\hline 6 & Rate of ammonification, $\rho_{6}$ & $\rho_{6}=K_{a} \cdot S_{N D} \cdot X_{B H}$ \\
\hline 7 & Rate of hydrolysis of substrate, $\rho_{7}$ & $\rho_{7}=K_{h} \cdot \frac{X_{s} / X_{B H}}{K_{X}+\left(X_{S} / X_{B H}\right)} \cdot\left[\frac{S_{O}}{S_{O}+K_{O H}}+\eta_{h} \cdot \frac{K_{O H}}{K_{O H}+S_{O}} \cdot \frac{S_{N O}}{S_{N O}+K_{N O}}\right] \cdot X_{B H}$ \\
\hline 8 & Rate of hydrolysis of particulate nitrogen, $\rho_{8}$ & $\rho_{8}=\rho_{7} \cdot\left(X_{N D} / X_{S}\right)$ \\
\hline 9 & Rate of hydrolysis of BAP, $\rho_{9}$ & $\rho_{9}=K_{h, B A P} \cdot \frac{S_{o}}{S_{O}+K_{O H}} \cdot S_{B A P} \cdot X_{B H}$ \\
\hline 10 & Rate of anoxic hydrolysis of BAP, $\rho_{10}$ & $\rho_{10}=K_{h, B A P} \cdot \eta_{h} \cdot \frac{K_{O H}}{K_{O H}+S_{0}} \cdot \frac{S_{N O}}{S_{N O}+K_{N O}} \cdot S_{B A P} \cdot X_{B H}$ \\
\hline 11 & Rate of aerobic hydrolysis of UAP, $\rho_{11}$ & $\rho_{11}=K_{h, U A P} \cdot \frac{S_{0}}{S_{0}+K_{O H}} \cdot S_{U A P} \cdot X_{B H}$ \\
\hline 12 & Rate of aerobic hydrolysis of UAP, $\rho_{12}$ & $\rho_{12}=K_{h, U A P} \cdot \eta_{h} \cdot \frac{K_{O H}}{K_{O H}+S_{O}} \cdot \frac{S_{N O}}{S_{N O}+K_{N O}} \cdot S_{U A P} \cdot X_{B H}$ \\
\hline
\end{tabular}

Table A.1

\begin{tabular}{|c|c|c|c|c|c|c|c|c|c|c|c|c|c|c|c|c|}
\hline \multirow[t]{3}{*}{$j$} & \multirow[t]{3}{*}{ Process } & \multicolumn{15}{|c|}{ Component, $i$} \\
\hline & & 1 & 2 & 3 & 4 & 5 & 6 & 7 & 8 & 9 & 10 & 11 & 12 & 13 & 14 & 15 \\
\hline & & $S_{i}$ & $S_{S}$ & $X_{i}$ & $X_{S}$ & $X_{B H}$ & $X_{B A}$ & $S_{B A P}$ & $S_{U A P}$ & $S_{O}$ & $S_{N O}$ & $S_{N H}$ & $S_{N D}$ & $X_{N D}$ & $S_{A L K}$ & $S_{N 2}$ \\
\hline 1 & $\begin{array}{l}\text { Aerobic growth of } \\
\text { heterotrophs }\end{array}$ & & $-\frac{1}{Y_{H}}$ & & & 1 & & & $\frac{f_{U A P}}{Y_{H}}$ & $-\frac{1-Y_{H}-f_{\text {UAP }}}{Y_{H}}$ & & $-i_{x b}$ & & & $-i_{x b} \cdot i_{\text {charge_NHx }}$ & \\
\hline 2 & $\begin{array}{l}\text { Anoxic growth of } \\
\text { heterotrophs }\end{array}$ & & $-\frac{1}{Y_{H}}$ & & & 1 & & & $\frac{f_{U A P}}{Y_{H}}$ & & $-\frac{1-Y_{H}-f_{U A P}}{2.86 \cdot Y_{H}}$ & $-i_{x b}$ & & & $\left(\frac{1-Y_{H}-f_{\text {UAP }}}{2.86 \cdot Y_{H}}--i_{x b}\right) i_{\text {charge } \_N H x}$ & $\frac{1-Y_{H}-f_{U A P}}{2.86 \cdot Y_{H}}$ \\
\hline 3 & $\begin{array}{l}\text { Aerobic growth of } \\
\text { autotrophs }\end{array}$ & & & & & & 1 & & $\frac{f_{U A P}}{Y_{A}}$ & $-\frac{4.57-Y_{A}-f_{U A P}}{Y_{A}}$ & $\frac{1}{Y_{A}}$ & $-i_{x b}-\frac{1}{Y_{A}}$ & & & $-i_{x b} \cdot i_{\text {charge_NHx }}-\frac{1}{7 \cdot Y_{A}}$ & \\
\hline 4 & Lysis of heterotrophs & & & $f_{p}$ & $1-f_{p}-f_{B A P}$ & -1 & & $f_{B A P}$ & & & & & & $i_{x b}-f_{p} \cdot i_{x p}$ & & \\
\hline 5 & Lysis of autotrophs & & & $f_{p}$ & $1-f_{p}-f_{B A P}$ & & -1 & $f_{B A P}$ & & & & & & $i_{x b}-f_{p} \cdot i_{x p}$ & & \\
\hline 6 & Ammonification & & & & & & & & & & & 1 & -1 & & $i_{\text {charge } \_N H x}$ & \\
\hline 7 & $\begin{array}{l}\text { Hydrolysis of } \\
\text { substrate }\end{array}$ & & 1 & & -1 & & & & & & & & & & & \\
\hline 8 & $\begin{array}{l}\text { Hydrolysis of } \\
\text { particulate } \\
\text { nitrogen }\end{array}$ & & & & & & & & & & & & 1 & -1 & & \\
\hline 9 & $\begin{array}{l}\text { Aerobic hydrolysis } \\
\text { of BAP }\end{array}$ & $f_{b}$ & $1-f_{b}$ & & & & & -1 & & & & & & & & \\
\hline 10 & $\begin{array}{l}\text { Anoxic hydrolysis } \\
\text { of BAP }\end{array}$ & $f_{b}$ & $1-f_{b}$ & & & & & -1 & & & & & & & & \\
\hline 11 & $\begin{array}{l}\text { Aerobic hydrolysis } \\
\text { of UAP }\end{array}$ & $f_{b}$ & $1-f_{b}$ & & & & & & -1 & & & & & & & \\
\hline 12 & $\begin{array}{l}\text { Aerobic hydrolysis } \\
\text { of UAP }\end{array}$ & $f_{b}$ & $1-f_{b}$ & & & & & & -1 & & & & & & & \\
\hline
\end{tabular}

Table A.2

Stoichiometry for biological processes $\left(i_{\text {charge_NHx }}=1 / 14\right)$

\section{Appendix B}

$$
\begin{aligned}
\frac{d X_{s}^{a n}}{d t}= & \frac{1}{V_{a n}} \cdot\left[Q_{\text {in }} \cdot X_{s}^{i n}+Q_{r} \cdot X_{s}^{a r}-\left(Q_{r}+Q_{o u t}\right) \cdot X_{s}^{a n}\right] \\
& +\left[\left(1-f_{p}-f_{B A P}\right) \cdot\left(\rho_{4}+\rho_{5}\right)-\rho_{7}\right]
\end{aligned}
$$

$$
\begin{aligned}
\frac{d S_{i}^{a n}}{d t}= & \frac{1}{V_{a n}} \cdot\left[Q_{i n} \cdot S_{i}^{i n}+Q_{r} \cdot S_{i}^{a r}-\left(Q_{r}+Q_{o u t}\right) \cdot S_{i}^{a n}\right]+\left[f _ { b } \cdot \left(\rho_{9}+\rho_{10}\right.\right. \\
& \left.\left.+\rho_{11}+\rho_{12}\right)\right]
\end{aligned}
$$$$
\frac{d X_{B H}^{a n}}{d t}=\frac{1}{V_{a n}} \cdot\left[Q_{i n} \cdot X_{B H}^{i n}+Q_{r} \cdot X_{B H}^{a r}-\left(Q_{r}+Q_{o u t}\right) \cdot X_{B H}^{a n}\right]
$$ 
$\frac{d X_{B A}^{a n}}{d t}=\frac{1}{V_{a n}} \cdot\left[Q_{i n} \cdot X_{B A}^{i n}+Q_{r} \cdot X_{B A}^{a r}-\left(Q_{r}+Q_{o u t}\right) \cdot X_{B A}^{a n}\right]+\left[\rho_{3}-\rho_{5}\right]$

$\frac{d S_{B A P}^{a n}}{d t}=\frac{1}{V_{a n}} \cdot\left[Q_{i n} \cdot S_{B A P}^{i n}+Q_{r} \cdot S_{B A P}^{a r}-\left(Q_{r}+Q_{o u t}\right) \cdot S_{B A P}^{a n}\right]$

$+\left[f_{B A P} \cdot\left(\rho_{4}+\rho_{5}\right)-\left(\rho_{9}+\rho_{10}\right)\right]$

$\frac{d S_{U A P}^{a n}}{d t}=\frac{1}{V_{a n}} \cdot\left[Q_{i n} \cdot S_{U A P}^{i n}+Q_{r} \cdot S_{U A P}^{a r}-\left(Q_{r}+Q_{o u t}\right) \cdot S_{U A P}^{a n}\right]$

$+\left[\frac{f_{U A P}}{Y_{H}} \cdot\left(\rho_{1}+\rho_{2}\right)+\frac{f_{U A P}}{Y_{A}} \cdot \rho_{3}-\left(\rho_{11}+\rho_{12}\right)\right]$

$$
\begin{aligned}
\frac{d S_{O}^{a n}}{d t}= & \frac{1}{V_{a n}} \cdot\left[Q_{i n} \cdot S_{O}^{i n}+Q_{r} \cdot S_{O}^{a r}-\left(Q_{r}+Q_{o u t}\right) \cdot S_{O}^{a n}\right] \\
& +\left[-\frac{1-Y_{H}-f_{U A P}}{Y_{H}} \cdot \rho_{1}-\frac{4.57-Y_{A}-f_{U A P}}{Y_{A}} \cdot \rho_{3}\right]
\end{aligned}
$$

$$
\begin{aligned}
\frac{d S_{N O}^{a n}}{d t}= & \frac{1}{V_{a n}} \cdot\left[Q_{i n} \cdot S_{N O}^{i n}+Q_{r} \cdot S_{N O}^{a r}-\left(Q_{r}+Q_{o u t}\right) \cdot S_{N O}^{a n}\right] \\
& +\left[-\frac{1-Y_{H}-f_{U A P}}{2.86 \cdot Y_{H}} \cdot \rho_{2}+\frac{1}{Y_{A}} \cdot \rho_{3}\right]
\end{aligned}
$$

$$
\begin{aligned}
\frac{d S_{N H}^{a n}}{d t}= & \frac{1}{V_{a n}} \cdot\left[Q_{i n} \cdot S_{N H}^{i n}+Q_{r} \cdot S_{N H}^{a r}-\left(Q_{r}+Q_{o u t}\right) \cdot S_{N H}^{a n}\right] \\
& +\left[-i_{x b} \cdot\left(\rho_{1}+\rho_{2}\right)-\left(i_{x b}+\frac{1}{Y_{A}}\right) \cdot \rho_{3}+\rho_{6}\right]
\end{aligned}
$$

$$
\frac{d S_{N D}^{a n}}{d t}=\frac{1}{V_{a n}} \cdot\left[Q_{i n} \cdot S_{N D}^{i n}+Q_{r} \cdot S_{N D}^{a r}-\left(Q_{r}+Q_{o u t}\right) \cdot S_{N D}^{a n}\right]+\left[-\rho_{6}+\rho_{8}\right]
$$

$$
\begin{aligned}
\frac{d X_{N D}^{a n}}{d t}= & \frac{1}{V_{a n}} \cdot\left[Q_{i n} \cdot X_{N D}^{i n}+Q_{r} \cdot X_{N D}^{a r}-\left(Q_{r}+Q_{o u t}\right) \cdot X_{N D}^{a n}\right] \\
& +\left[\left(i_{x b}-f_{p} \cdot i_{x p}\right) \cdot\left(\rho_{4}+\rho_{5}\right)-\rho_{8}\right]
\end{aligned}
$$

$$
\begin{aligned}
\frac{d S_{A L K}^{a n}}{d t}= & \frac{1}{V_{a n}} \cdot\left[Q_{i n} \cdot S_{A L K}^{i n}+Q_{r} \cdot S_{A L K}^{a r}-\left(Q_{r}+Q_{o u t}\right) \cdot S_{A L K}^{a n}\right] \\
& +\left[-\frac{i_{x b}}{14} \cdot \rho_{1}+\left(\frac{1-Y_{H}}{14 \cdot 2.86 \cdot Y_{H}}-\frac{i_{x b}}{14}\right) \cdot \rho_{2}\right. \\
& \left.-\left(\frac{i_{x b}}{14}+\frac{1}{7 \cdot Y_{A}}\right) \cdot \rho_{3}+\frac{1}{14} \cdot \rho_{6}\right]
\end{aligned}
$$$$
\frac{d S_{N 2}^{a n}}{d t}=\frac{1}{V_{a n}} \cdot\left[Q_{i n} \cdot S_{N 2}^{i n}+Q_{r} \cdot S_{N 2}^{a r}-\left(Q_{r}+Q_{o u t}\right) \cdot S_{N 2}^{a n}\right]
$$$$
+\left[\frac{1-Y_{H}-f_{U A P}}{2.86 \cdot Y_{H}} \cdot \rho_{2}\right]
$$

$$
\begin{aligned}
\frac{d S_{i}^{a r}}{d t}= & \frac{1}{V_{\text {ar }}} \cdot\left[\left(Q_{r}+Q_{\text {out }}\right) \cdot S_{i}^{a r}-Q_{\text {out }} \cdot f \cdot S_{i}^{a r}-Q_{r} \cdot S_{i}^{a r}\right]+\left[f _ { b } \cdot \left(\rho_{9}\right.\right. \\
& \left.\left.+\rho_{10}+\rho_{11}+\rho_{12}\right)\right]
\end{aligned}
$$

$$
\begin{aligned}
\frac{d S_{s}^{a r}}{d t}= & \frac{1}{V_{a r}} \cdot\left[\left(Q_{r}+Q_{\text {out }}\right) \cdot S_{s}^{a r}-Q_{\text {out }} \cdot f \cdot S_{s}^{a r}-Q_{r} \cdot S_{s}^{a r}\right] \\
& +\left[-\frac{1}{Y_{H}} \cdot \rho_{1}-\frac{1}{Y_{H}} \cdot \rho_{2}+\rho_{7}+\left(1-f_{b}\right) \cdot\left(\rho_{9}+\rho_{10}+\rho_{11}+\rho_{12}\right)\right]
\end{aligned}
$$

$$
\frac{d X_{i}^{a r}}{d t}=\frac{1}{V_{a r}} \cdot\left[\left(Q_{r}+Q_{o u t}\right) \cdot X_{i}^{a r}-Q_{r} \cdot X_{i}^{a r}\right]+\left[f_{p} \cdot\left(\rho_{4}+\rho_{5}\right)\right]
$$

$$
\begin{aligned}
\frac{d X_{s}^{a r}}{d t}= & \frac{1}{V_{a r}} \cdot\left[\left(Q_{r}+Q_{o u t}\right) \cdot X_{s}^{a r}-Q_{r} \cdot X_{s}^{a r}\right]+\left[\left(1-f_{p}\right.\right. \\
& \left.\left.-f_{B A P}\right) \cdot\left(\rho_{4}+\rho_{5}\right)-\rho_{7}\right]
\end{aligned}
$$

$$
\frac{d X_{B H}^{a r}}{d t}=\frac{1}{V_{a r}} \cdot\left[\left(Q_{r}+Q_{o u t}\right) \cdot X_{B H}^{a r}-Q_{r} \cdot X_{B H}^{a r}\right]+\left[\rho_{1}+\rho_{2}-\rho_{4}\right]
$$

$$
\frac{d X_{B A}^{a r}}{d t}=\frac{1}{V_{a r}} \cdot\left[\left(Q_{r}+Q_{o u t}\right) \cdot X_{B A}^{a r}-Q_{r} \cdot X_{B A}^{a r}\right]+\left[\rho_{3}-\rho_{5}\right]
$$

$$
\begin{aligned}
\frac{d S_{B A P}^{a r}}{d t}= & \frac{1}{V_{a r}} \cdot\left[\left(Q_{r}+Q_{o u t}\right) \cdot S_{B A P}^{a r}-Q_{o u t} \cdot f \cdot S_{B A P}^{a r}-Q_{r} \cdot S_{B A P}^{a r}\right] \\
& +\left[f_{B A P} \cdot\left(\rho_{4}+\rho_{5}\right)-\left(\rho_{9}+\rho_{10}\right)\right]
\end{aligned}
$$

$$
\begin{aligned}
\frac{d S_{U A P}^{a r}}{d t}= & \frac{1}{V_{a r}} \cdot\left[\left(Q_{r}+Q_{o u t}\right) \cdot S_{U A P}^{a r}-Q_{o u t} \cdot f \cdot S_{U A P}^{a r}-Q_{r} \cdot S_{U A P}^{a r}\right] \\
& +\left[\frac{f_{U A P}}{Y_{H}} \cdot\left(\rho_{1}+\rho_{2}\right)+\frac{f_{U A P}}{Y_{A}} \cdot \rho_{3}-\left(\rho_{11}+\rho_{12}\right)\right]
\end{aligned}
$$

$$
\begin{aligned}
\frac{d S_{O}^{a r}}{d t}= & \frac{1}{V_{a r}} \cdot\left[\left(Q_{r}+Q_{o u t}\right) \cdot S_{O}^{a r}-Q_{o u t} \cdot S_{O}^{a r}-Q_{r} \cdot S_{O}^{a r}\right]+\text { OTR } \\
& +\left[-\frac{1-Y_{H}-f_{U A P}}{Y_{H}} \cdot \rho_{1}-\frac{4.57-Y_{A}-f_{U A P}}{Y_{A}} \cdot \rho_{3}\right]
\end{aligned}
$$

$$
\begin{aligned}
\frac{d S_{N O}^{a r}}{d t}= & \frac{1}{V_{a r}} \cdot\left[\left(Q_{r}+Q_{o u t}\right) \cdot S_{N O}^{a r}-Q_{o u t} \cdot S_{N O}^{a r}-Q_{r} \cdot S_{N O}^{a r}\right] \\
& +\left[-\frac{1-Y_{H}-f_{U A P}}{2.86 \cdot Y_{H}} \cdot \rho_{2}+\frac{1}{Y_{A}} \cdot \rho_{3}\right]
\end{aligned}
$$

$$
\begin{aligned}
\frac{d S_{N H}^{a r}}{d t}= & \frac{1}{V_{a r}} \cdot\left[\left(Q_{r}+Q_{o u t}\right) \cdot S_{N H}^{a r}-Q_{o u t} \cdot S_{N H}^{a r}-Q_{r} \cdot S_{N H}^{a r}\right] \\
& +\left[-i_{x b} \cdot\left(\rho_{1}+\rho_{2}\right)-\left(i_{x b}+\frac{1}{Y_{A}}\right) \cdot \rho_{3}+\rho_{6}\right]
\end{aligned}
$$

$$
\frac{d S_{N D}^{a r}}{d t}=\frac{1}{V_{a r}} \cdot\left[\left(Q_{r}+Q_{o u t}\right) \cdot S_{N D}^{a r}-Q_{o u t} \cdot S_{N D}^{a r}-Q_{r} \cdot S_{N D}^{a r}\right]+\left[-\rho_{6}+\rho_{8}\right]
$$

$$
\begin{aligned}
\frac{d X_{N D}^{a r}}{d t}= & \frac{1}{V_{a r}} \cdot\left[\left(Q_{r}+Q_{o u t}\right) \cdot X_{N D}^{a r}-Q_{r} \cdot X_{N D}^{a r}\right] \\
& +\left[\left(i_{x b}-f_{p} \cdot i_{x p}\right) \cdot\left(\rho_{4}+\rho_{5}\right)-\rho_{8}\right]
\end{aligned}
$$




$$
\begin{aligned}
\frac{d S_{A L K}^{a r}}{d t}= & \frac{1}{V_{a r}} \cdot\left[\left(Q_{r}+Q_{o u t}\right) \cdot S_{A L K}^{a r}+q_{A L K}^{a d d} \cdot S_{A L K}^{a d d}-Q_{o u t} \cdot S_{A L K}^{a r}\right. \\
& \left.-Q_{r} \cdot S_{A L K}^{a r}\right]+\left[-\frac{i_{x b}}{14} \cdot \rho_{1}+\left(\frac{1-Y_{H}}{14 \cdot 2.86 \cdot Y_{H}}-\frac{i_{x b}}{14}\right) \cdot \rho_{2}\right. \\
& \left.-\left(\frac{i_{x b}}{14}+\frac{1}{7 \cdot Y_{A}}\right) \cdot \rho_{3}+\frac{1}{14} \cdot \rho_{6}\right]
\end{aligned}
$$

$$
\begin{aligned}
\frac{d S_{N 2}^{a r}}{d t}= & \frac{1}{V_{a r}} \cdot\left[\left(Q_{r}+Q_{o u t}\right) \cdot S_{N 2}^{a r}-Q_{o u t} \cdot f \cdot S_{N 2}^{a r}-Q_{r} \cdot S_{N 2}^{a r}\right] \\
& +\left[\frac{1-Y_{H}-f_{U A P}}{2.86 \cdot Y_{H}} \cdot \rho_{2}\right]
\end{aligned}
$$

\section{References}

Abegglen, C., Ospelt, M., Siegrist, H., 2008. Biological nutrient removal in a smallscale MBR treating household wastewater. Water Res. 42, 338-346. http:// dx.doi.org/10.1016/j.watres.2007.07.020.

Agathos, S.N. Reineke, W. 2003. Biotechnology for the Environment: Wastewater Treatment and Modeling, Waste Gas Handling. Kluwer Academic Publishers.

Autonomous Net-Zero Water Project [WWW Document], 2017. URL http://www. coe.miami.edu/wqel/netzero/results.html.

Baek, S.H., Jeon, S.K., Pagilla, K., 2009. Mathematical modeling of aerobic membrane bioreactor (MBR) using activated sludge model no. 1 (ASM1). J. Ind. Eng. Chem. 15, 835-840. http://dx.doi.org/10.1016/j.jiec.2009.09.009.

Benyahia, B., Sari, T., Cherki, B., Harmand, J., 2013. Anaerobic membrane bioreactor modeling in the presence of soluble microbial products (SMP) - the anaerobic model AM2b. Chem. Eng. J. 228, 1011-1022. http://dx.doi.org/10.1016/ j.cej.2013.05.073.

Capodici, M., Di Bella, G., Di Trapani, D., Torregrossa, M., 2015. Pilot scale experiment with MBR operated in intermittent aeration condition: analysis of biological performance. Bioresour. Technol. 177, 398-405. http://dx.doi.org/10.1016/ j.biortech.2014.11.075.

Cosenza, A., Mannina, G., Neumann, M.B., Viviani, G., Vanrolleghem, P.A., 2013. Biological nitrogen and phosphorus removal in membrane bioreactors: model development and parameter estimation. Bioprocess Biosyst. Eng. 36, 499-514. http://dx.doi.org/10.1007/s00449-012-0806-1.

Dalmau, M., Rodriguez-Roda, I., Ayesa, E., Odriozola, J., Sancho, L., Comas, J., 2013. Development of a decision tree for the integrated operation of nutrient removal MBRs based on simulation studies and expert knowledge. Chem. Eng. J. 217, 174-184. http://dx.doi.org/10.1016/j.cej.2012.11.060.

Di Bella, G., Mannina, G., Viviani, G., 2008. An integrated model for physicalbiological wastewater organic removal in a submerged membrane bioreactor: model development and parameter estimation. J. Memb. Sci. 322, 1-12. http:// dx.doi.org/10.1016/j.memsci.2008.05.036.

Englehardt, J.D., Wu, T., Tchobanoglous, G., 2013. Urban net-zero water treatment and mineralization: experiments, modeling and design. Water Res. 47, 4680-4691. http://dx.doi.org/10.1016/j.watres.2013.05.026.

EPA, U., 2015. US Environmental Protection Agency.

Fenu, A., Guglielmi, G., Jimenez, J., Spèrandio, M., Saroj, D., Lesjean, B., Brepols, C. Thoeye, C., Nopens, I., 2010. Activated sludge model (ASM) based modelling of membrane bioreactor (MBR) processes: a critical review with special regard to MBR specificities. Water Res. 44, 4272-4294. http://dx.doi.org/10.1016/ j.watres.2010.06.007.

Fuerhacker, M., Bauer, H., Ellinger, R., Sree, U., Schmid, H., Zibuschka, F., Puxbaum, H., 2000. Approach for a novel control strategy for simultaneous nitrification/denitrification in activated sludge reactors. Water Res. 34, 2499-2506. http://dx.doi.org/10.1016/S0043-1354(00)00016-6.

Gassie, L.W., Englehardt, J.D., Wang, J., Brinkman, N., Garland, J., Gardinali, P., Guo, T., 2016. Mineralizing urban net-zero water treatment: phase II field results and design recommendations. Water Res. 105, 496-506. http://dx.doi.org/10.1016/ j.watres.2016.09.005.

Grady, C.P.L., Daigger, G.T., Lim, H.C., 1999. Biological Wastewater Treatment, second ed. Marcel Dekker, Inc., New York

Hai, F.I., Yamamoto, K., Lee, C.-H., 2014. Membrane Biological Reactors Theory, Modeling, Design, Management and Applications to Wastewater Reuse. IWA Publishing.

Hauduc, H., Rieger, L., Takacs, I., Heduit, A., Vanrolleghem, P.A., Gillot, S., 2010. A systematic approach for model verification: application on seven published activated sludge models. Water Sci. Technol. 61, 825-839. http://dx.doi.org/ 10.2166/wst.2010.898

Henze, M., Gujer, W., Mino, T., van Loosdrecht, M., 2000. Activated Sludge Models ASM1, ASM2, ASM2d and ASM3. IWA Publishing.
Henze, M., Loosdrecht, M.C.M., Ekama, G.A., Brdjanovic, D., 2008. Biological Wastewater Treatment: Principles, Modelling and Design. IWA Publishing.

Ivanov, V., 2011. Environmental Microbiology for Engineers. Taylor \& Francis Group.

Jiang, T., Myngheer, S., De Pauw, D.J.W., Spanjers, H., Nopens, I., Kennedy, M.D. Amy, G., Vanrolleghem, P.A., 2008. Modelling the production and degradation of soluble microbial products (SMP) in membrane bioreactors (MBR). Water Res. 42, 4955-4964. http://dx.doi.org/10.1016/j.watres.2008.09.037.

Judd, S., 2010. The MBR Book: Principles and Applications of Membrane Bioreactors for Water and Wastewater Treatment. Butterworth-Heinemann.

Keskitalo, J., Jansen, J.L.C., Leiviskä, K., 2010. Calibration and validation of a modified ASM1 using long-term simulation of a full-scale pulp mill wastewater treatment plant. Environ. Technol. 31, 555-566. http://dx.doi.org/10.1080/ 09593330903563802.

Kim, H.G., Jang, H.N., Kim, H.M., Lee, D.S., Eusebio, R.C., Kim, H.S., Chung, T.H., 2010. Enhancing nutrient removal efficiency by changing the internal recycling ratio and position in a pilot-scale MBR process. Desalination 262, 50-56. http:// dx.doi.org/10.1016/j.desal.2010.05.040.

Kim, H.S., Seo, I.S., Kim, Y.K., Kim, J.Y., Ahn, H.W., Kim, I.S., 2007. Full-scale study on dynamic state membrane bio-reactor with modified intermittent aeration. Desalination 202, 99-105. http://dx.doi.org/10.1016/j.desal.2005.12.044.

Koch, G., Kühni, M., Gujer, W., Siegrist, H., 2000. Calibration and validation of activated sludge model no. 3 for Swiss municipal wastewater. Water Res. 34 3580-3590. http://dx.doi.org/10.1016/S0043-1354(00)00105-6.

Li, B., Irvin, S., 2007. The comparison of alkalinity and ORP as indicators for nitrification and denitrification in a sequencing batch reactor (SBR). Biochem. Eng. J. 34, 248-255. http://dx.doi.org/10.1016/j.bej.2006.12.020.

Lim, B.S., Choi, B.C., Yu, S.W., Lee, C.G., 2007. Effects of operational parameters on aeration on/off time in an intermittent aeration membrane bioreactor. Desalination 202, 77-82. http://dx.doi.org/10.1016/j.desal.2005.12.041.

Lo, C.K., Yu, C.W., Tam, N.F.Y., Traynor, S., 1994. Enhanced nutrient removal by oxidation-reduction potential (ORP) controlled aeration in a laboratory scale extended aeration treatment system. Water Res. 28, 2087-2094. http:// dx.doi.org/10.1016/0043-1354(94)90018-3.

Mannina, G., Capodici, M., Cosenza, A., Di Trapani, D., 2016. Carbon and nutrient biological removal in a University of Cape Town membrane bioreactor: analysis of a pilot plant operated under two different C/N ratios. Chem. Eng. J. 296 289-299. http://dx.doi.org/10.1016/j.cej.2016.03.114.

Mannina, G., Cosenza, A., Vanrolleghem, P.A., Viviani, G., 2011a. A practical protocol for calibration of nutrient removal wastewater treatment models. J. Hydroinform. 13, 575. http://dx.doi.org/10.2166/hydro.2011.041.

Mannina, G., Di Bella, G., Viviani, G., 2011b. An integrated model for biological and physical process simulation in membrane bioreactors (MBRs). J. Memb. Sci. 376, 56-69. http://dx.doi.org/10.1016/j.memsci.2011.04.003.

Mannina, G., Di Bella, G., Viviani, G., 2010. Uncertainty assessment of a membrane bioreactor model using the GLUE methodology. Biochem. Eng. J. 52, 263-275. http://dx.doi.org/10.1016/j.bej.2010.09.001.

Manser, R., Gujer, W., Siegrist, H., 2006. Decay processes of nitrifying bacteria in biological wastewater treatment systems. Water Res. 40, 2416-2426. http:// dx.doi.org/10.1016/j.watres.2006.04.019.

Olsson, G., Newell, B., 1999. Wastewater Treatment Systems: Modelling, Diagnosis and Control. IWA Publishing.

Peng, Y.Z., Ma, Y., Wang, S.Y., 2007. Denitrification potential enhancement by addition of external carbon sources in a pre-denitrification process. J. Environ. Sci. 19, 284-289. http://dx.doi.org/10.1016/S1001-0742(07)60046-1.

Sun, S.-P., Nàcher, C.P.I., Merkey, B., Zhou, Q., Xia, S.-Q., Yang, D.-H., Sun, J.-H., Smets, B.F., 2010. Effective biological nitrogen removal treatment processes for domestic wastewaters with low C/N ratios: a review. Environ. Eng. Sci. 27 111-126. http://dx.doi.org/10.1089/ees.2009.0100.

Tchobanoglous, G., Abu-Orf, M., Burton, F.L., Bowden, G., Stensel, H.D., Metcalf, Eddy, Tsuchihashi, R., Pfrang, W., 2014. Wastewater Engineering: Treatment and Resource Recovery, fifth ed. McGraw-Hill, New York.

Tchobanoglous, G., Burton, F.L., Stensel, H.D., Metcalf, Eddy, I., 2003. Wastewater Engineering: Treatment and Reuse, fourth ed. McGraw-Hill, New York.

World Health Organization, 2008. WHO Guidelines for Drinking-water Quality. World Health Organization, Geneva. http://dx.doi.org/10.1016/S1462-0758(00) 00006-6.

Wu, T., Englehardt, J.D., 2016. Mineralizing urban net-zero water treatment: field experience for energy-positive water management. Water Res. 106, 352-363. http://dx.doi.org/10.1016/j.watres.2016.10.015.

Wu, T., Englehardt, J.D., 2015. Peroxone mineralization of chemical oxygen demand for direct potable water reuse: kinetics and process control. Water Res. 73, 362-372. http://dx.doi.org/10.1016/j.watres.2015.01.030.

Zarragoitia-González, A., Schetrite, S., Alliet, M., Jáuregui-Haza, U., Albasi, C., 2008 Modelling of submerged membrane bioreactor: conceptual study about link between activated slugde biokinetics, aeration and fouling process. J. Memb. Sci. 325, 612-624. http://dx.doi.org/10.1016/j.memsci.2008.08.037.

Zuthi, M.F.R., Ngo, H.H., Guo, W.S., Zhang, J., Liang, S., 2013. A review towards finding a simplified approach for modelling the kinetics of the soluble microbia products (SMP) in an integrated mathematical model of membrane bioreactor (MBR). Int. Biodeterior. Biodegr. 85, 466-473. http://dx.doi.org/10.1016/ j.ibiod.2013.03.032. 